Original article

\title{
Design, synthesis and antibacterial activity of minor groove binders: The role of non-cationic tail groups
}

\author{
Abedawn I. Khalaf ${ }^{\mathrm{a}, *}$, Claire Bourdin ${ }^{\mathrm{a}}$, David Breen ${ }^{\mathrm{a}}$, Gavin Donoghue ${ }^{\mathrm{a}}$, Fraser J. Scott ${ }^{\mathrm{a}}$, Colin J. Suckling ${ }^{\mathrm{a}}$, \\ Donna MacMillan ${ }^{\mathrm{a}}$, Carol Clements ${ }^{\mathrm{b}}$, Keith Fox ${ }^{\mathrm{c}}$, Doreen A.T. Sekibo ${ }^{\mathrm{c}}$ \\ ${ }^{a}$ WestCHEM, Department of Pure and Applied Chemistry, University of Strathclyde, 295 Cathedral Street, Glasgow, G1 1XL, UK \\ ${ }^{\mathrm{b}}$ Department of Pharmaceutical Sciences, University of Strathclyde, 27 Taylor Street, Glasgow G4 ONR, UK \\ ${ }^{\mathrm{c}}$ Centre for Biological Sciences, Life Science Building, University of Southampton, Southampton SO17 1BJ, UK
}

\section{A R T I C L E I N F O}

\section{Article history:}

Received 4 May 2012

Received in revised form

31 July 2012

Accepted 8 August 2012

Available online 16 August 2012

\section{Keywords:}

Minor groove binders

Antibacterial

DNase I footprinting

hERG

Nitroalkene

\begin{abstract}
A B S T R A C T
The design and synthesis of a new class of minor groove binder (MGBs) in which, the cationic tail group has been replaced by a neutral, polar variant including cyanoguanidine, nitroalkene, and trifluoroacetamide groups. Antibacterial activity (against Gram positive bacteria) was found for both the nitroalkene and trifluoroacetamide groups. For the case of the nitroalkene tail group, strong binding of a minor groove binder containing this tail group was demonstrated by both DNA footprinting and melting temperature measurements, showing a correlation between DNA binding and antibacterial activity. The compounds have also been evaluated for binding to the hERG ion channel to determine whether non-cationic but polar substituents might have an advantage compared with conventional cationic tail groups in avoiding hERG binding. In this series of compounds, it was found that whilst non-cationic compounds generally had lower affinity to the hERG ion channel, all of the compounds studied bound weakly to the hERG ion channel, probably associated with the hydrophobic head groups.
\end{abstract}

(C) 2012 Elsevier Masson SAS. All rights reserved.

\section{Introduction}

Minor groove binders (MGBs) developed from distamycin $\mathbf{1}$ as a prototype have been shown to be potent antibacterial agents both in vitro and in vivo in our laboratories [1,2]. The most active compounds are characterized by containing a hydrophobic $\mathrm{N}$ terminal group in which one of the amide links in distamycin has been replaced by the alkene isostere $(\mathbf{2}-\mathbf{4})$. An additional key property in the profile of these compounds is the weakly basic $N$ alkylmorpholine as the tail group. Compared with alkyl tertiary amine and guanidine tail groups, these compounds are both more active against bacterial cells and less toxic to mammalian cell lines. Although the reasons for this behaviour are not known, it is clear that the physicochemical properties of such minor groove binders play a major role in their antibacterial activity [3]. Extending the argument; it would be interesting, therefore, to determine whether compounds containing neutral tail groups could retain antibacterial activity. Such compounds might conceivably have different cell permeation properties and pharmacokinetic properties. Moreover,

\footnotetext{
* Corresponding author. Tel.: +44 (0) 141548 2520; fax: +44 (0) 1415485743.

E-mail address: abedawn.khalaf@strath.ac.uk (A.I. Khalaf).
}

lacking the cationic group at physiological $\mathrm{pH}$, they might avoid binding to the hERG (the human Ether-à-go-go-Related Gene) ion channel, thereby removing a significant risk for their development as drugs. This potassium ion channel has become a major anti-target for the pharmaceutical industry due to drug interactions with it being linked with induced long QT syndrome, a potentially fatal arrhythmia of the heart. Molecules containing basic nitrogen atoms are known to have a high likelihood of interacting with hERG; accordingly, we have prepared a group of non-cationic minor groove binders with neutral tail groups attached to the three backbones that gave highest antibacterial activity in earlier studies [4].

\section{Results and discussion}

\subsection{Compound selection}

In designing minor groove binders, it has generally been accepted that the cationic tail group forms strong ionic interactions with DNA [5]. It has also been found in structural studies using NMR that in solution, the alkylamino tail group is relatively mobile [2]. Consequently, unlike the backbone structure of the minor groove binder where specific hydrogen bonding has been characterized and discussed [6] the interactions of tail groups with DNA have not 
<smiles>Cn1cc(NC(=O)c2cc(NC=O)cn2C)cc1C(=O)NCCC(N)=[NH2+]</smiles>

distamycin 1<smiles>COc1cccc(/C=C/c2ccc(C(=O)Nc3cc(C(=O)Nc4cc(C(=O)NCCN5CCOCC5)n(C)c4)n(C)c3)cc2)c1</smiles>

3

been well defined. This gives considerable freedom to undertake an exploration of non-cationic tail groups in the context of antibacterial activity. The following were selected based upon a combination of synthetic accessibility and precedent in medicinal chemistry:

Hydroxyl - small, neutral, and hydrogen bond donor and acceptor, Acetoxy - small, neutral, and hydrogen bond acceptor,

BOC-amino - large, hydrophobic, neutral, and hydrogen bond donor and acceptor,

Trifluoroacetamido - small, dipolar, and hydrogen bond donor and acceptor,

Nitroalkene - large, dipolar, and hydrogen bond donor and acceptor,

Cyanoguanidine - large, dipolar, and hydrogen bond donor and acceptor,

The primary amino group (a synthetic precursor) and the guanidine group (a comparator for the nitroalkene and cyanoguanidine) were also examined.

\subsection{Synthesis}

The synthesis of the required compounds followed the strategy of coupling the alkene-containing head group dimers to protected dipyrrole amides with a suitably protected tail group (BOC amino or acetoxy). Coupling reactions were carried out using HBTU, the aryl dimer acid chloride [7], or T3P [8]. Cleavage of the tail group and subsequent elaboration using appropriate reagents [14,15] afforded the required compounds in moderate yields after HPLC purification (Scheme 1).

\subsection{Antibacterial activity}

The antibacterial activity of the compounds obtained was evaluated in our laboratories using the methods described previously. No activity was found with any compound against Gram negative bacteria. The results obtained against Staphylococcus aureus as a representative Gram positive bacterium are given in Table 1.<smiles></smiles>

2a $\mathrm{R}=$ morpholinyl 2b R $=\mathrm{CH}_{2} \mathrm{NMe}_{2}$<smiles>COc1ccc(/C=C/c2ccc(C(=O)Nc3cc(C(=O)Nc4cc(C(=O)NCCN5CCOCC5)n(C)c4)n(C)c3)cn2)cc1</smiles>

4

Unsurprisingly, no antibacterial activity was observed for compounds bearing simple hydroxyl or acetoxy tail groups (9a,b, $\mathbf{1 6 a}, \mathbf{b})$, nor for the one BOC-amino compound tested (8b). It was surprising, however, that the primary amino tail group did not lead to any antibacterial activity (10c), although it would be expected to be positively charged under the conditions of the assay. It is important to remember, however, that antibacterial activity may require not only binding to DNA but also penetration of the bacterial cell wall. Whilst there is no evidence in this class of compounds to suggest why, it is possible that the primary amine does not accumulate in the target cells whereas the corresponding tertiary amines do, in the case of $\mathbf{2}$, giving exceptionally strong antiGram positive activity. No activity was found with the cyanoguanidine examples (12b,c); this may reflect the particular combination of components in this minor groove binder rather than any intrinsic property of the cyanoguanidine. Nevertheless, minor groove binders with both nitroalkenyl (11a,c) and trifluoroacetamido (14c) tail groups showed significant antibacterial activity. Consistent with trends in previous studies [2], the antibacterial activity of the compound containing the quinolyl head group with the nitroalkene tail (11c) was notably greater than the others. An MIC of $1-2 \mu \mathrm{M}$ in these tests would be significant enough to warrant further evaluation were it not for the fact that the parent compound (2a) is an order of magnitude more potent still. Nevertheless, it is remarkable in terms of conventional views of the properties of minor groove binders that such activity is seen at all and raises questions as to whether these compounds with neutral tail groups do actually bind to DNA in a similar manner to related cationic minor groove binders. This question has been investigated using both footprinting studies and melting temperature studies.

\subsection{DNA binding}

The direct binding of the 3-quinolyl MGBs (11c) and (13c), which have nitroalkene and amidine tail groups respectively has been studied before [11,12]. Using the HexA and HexB polydeoxyribonucleotides as 


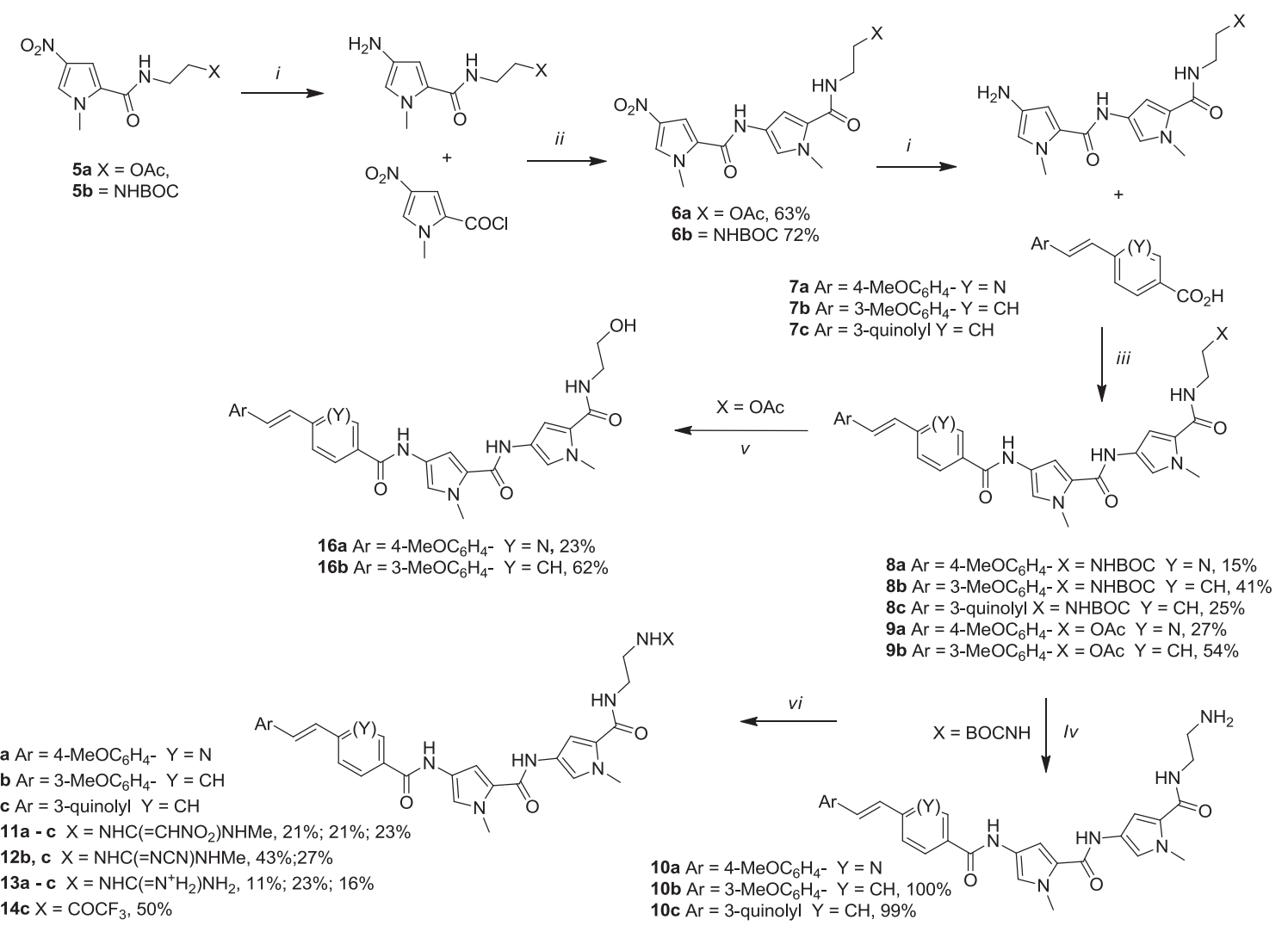

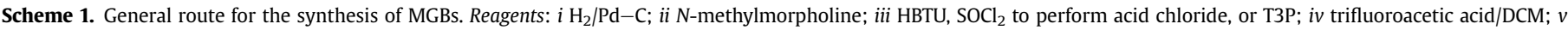
$\mathrm{LiOH}$; vi as appropriate, phenyl $N^{\prime}$-cyano- $N$-methylimidocarbamate, methylimidothiocarbonate salt, or trifluoroacetic anhydride.

targets, it was found that both (11c) and (13c) bind significantly to DNA predominantly at AT rich sites, as would be expected from their structures (Figs. 1 and 2). Fig. 1 shows DNase I digestion of the HexA and HexARev fragment in the presence of compounds 11c and 13c. Both of

Table 1

Synthetic methods and biological activity of MGBs prepared. Coupling methods: $\mathrm{A}=\mathrm{HBTU}, \mathrm{B}=$ acid chloride, $\mathrm{C}=\mathrm{T} 3 \mathrm{P}$; $\mathrm{NI}=$ not isolated, nd = not determined antibacterial activity of compounds tested against $S$. aureus. Results are given as MIC $(\mu \mathrm{M}) . \mathrm{NA}=$ not active. $\mathrm{nd}=$ not determined. Inhibition of hERG ion channel: compounds were assessed at $10 \mu \mathrm{M}$ and \% displacement of $\left[{ }^{3} \mathrm{H}\right]$-astemizole is reported. Each assay was run in triplicate and 3 separate experiments were carried out $(n=3)$.

\begin{tabular}{|c|c|c|c|c|c|c|}
\hline No. & $\mathrm{Ar}^{1}$ & $\mathrm{Ar}^{2}$ & Tail & Method & S. aureus & $h E R G$ \\
\hline 3 & 3-OMe phenyl & Phenyl & Ethyl morpholine & A & 2.0 & 65 \\
\hline 4 & 4-OMe phenyl & 2-Pyridyl & Ethyl morpholine & A & 6.25 & 58 \\
\hline $2 a$ & 3-Quinolyl & Phenyl & Ethyl morpholine & A & 0.12 & 65 \\
\hline 2b & 3-Quinolyl & Phenyl & DMAP & A & 25 & 60 \\
\hline $8 \mathbf{a}$ & 4-OMe phenyl & 2-Pyridyl & NHBOC & A & nd & nd \\
\hline $8 \mathbf{b}$ & 3-OMe phenyl & Phenyl & NHBOC & $\mathrm{C}$ & NA & 36 \\
\hline $8 c$ & 3-Quinolyl & Phenyl & NHBOC & A & nd & nd \\
\hline 10a & 4-OMe phenyl & 2-Pyridyl & $\mathrm{NH}_{2}$ & NI & nd & nd \\
\hline 10b & 3-OMe phenyl & Phenyl & $\mathrm{NH}_{2}$ & - & nd & nd \\
\hline $10 \mathrm{c}$ & 3-Quinolyl & Phenyl & $\mathrm{NH}_{2}$ & - & NA & 55 \\
\hline 11a & 4-OMe phenyl & 2-Pyridyl & Nitroalkene & - & 31 & nd \\
\hline 11b & 3-OMe phenyl & Phenyl & Nitroalkene & - & NA & nd \\
\hline 11c & 3-quinolyl & Phenyl & Nitroalkene & - & 2.5 & 51 \\
\hline 12b & 3-OMe phenyl & Phenyl & Cyanoguanidine & - & NA & 58 \\
\hline $12 c$ & 3-Quinolyl & Phenyl & Cyanoguanidine & - & NA & 54 \\
\hline 13a & 4-OMe phenyl & 2-Pyridyl & Guanidine & - & NA & nd \\
\hline 13b & 3-OMe phenyl & Phenyl & Guanidine & - & 25 & 69 \\
\hline $13 c$ & 3-Quinolyl & Phenyl & Guanidine & - & 7.8 & nd \\
\hline $14 c$ & 3-Quinolyl & Phenyl & Trifluoroacetamide & A & 12.5 & 24 \\
\hline $9 a$ & 4-OMe phenyl & 2-Pyridyl & Acetoxy & B & NA & nd \\
\hline 16a & 4-OMe phenyl & 2-Pyridyl & Hydroxy & - & NA & nd \\
\hline $9 b$ & 3-OMe phenyl & Phenyl & Acetoxy & C & NA & nd \\
\hline $16 b$ & 3-OMe phenyl & Phenyl & Hydroxy & - & NA & 32 \\
\hline
\end{tabular}

these ligands produce clear regions of protection (as indicated by the bars in this Figure). The regions of protection are summarised alongside the sequence in Fig. 2, in which it can be seen that the binding sites are predominantly in AT-rich regions, common to other minor groove binders such as distamycin. Both ligands produce footprints at similar sites at concentrations below $10 \mu \mathrm{M}$, though in general the protections with $13 \mathrm{c}$ persist to lower ligand concentrations. These results support a close connection between antibacterial activity and DNA binding. To complement the footprinting study, the same two compounds were evaluated for DNA binding by measuring the change in melting temperature of the oligonucleotide, 5'-GCGATATATGCG- $3^{\prime}$ and its complement. A substantial increase of $16{ }^{\circ} \mathrm{C}$ was measured for the nitroalkene 11c and an exceptionally large increase of $29^{\circ} \mathrm{C}$ was observed for the amidine 13c. These results are consistent with the intensity of the footprinting observed. Taken in isolation, it would be expected on the basis of ionic interactions that 11c would bind to DNA more strongly than $\mathbf{1 3 c}$. However the antibacterial activity of $\mathbf{1 3 c}$ is somewhat greater than that of 11c, the opposite of what is observed in DNA binding. Moreover the other guanidines examined in this study did not show measurable antibacterial activity. It can be hypothesized that this difference is due to the relative accessibility of the minor groove binders to DNA in the target bacterial cells. The quinolyl head group evidently provides favourable properties, and this could be due to favourable cell penetration, to resistance to efflux pumping, or to a combination of the two.

\section{Conclusion}

The results here show that it is possible for a non-cationic minor groove binder developed from the structure of distamycin both to bind to DNA and to result in significant antibacterial activity. These minor groove binders with nitroalkenyl tail groups therefore are 

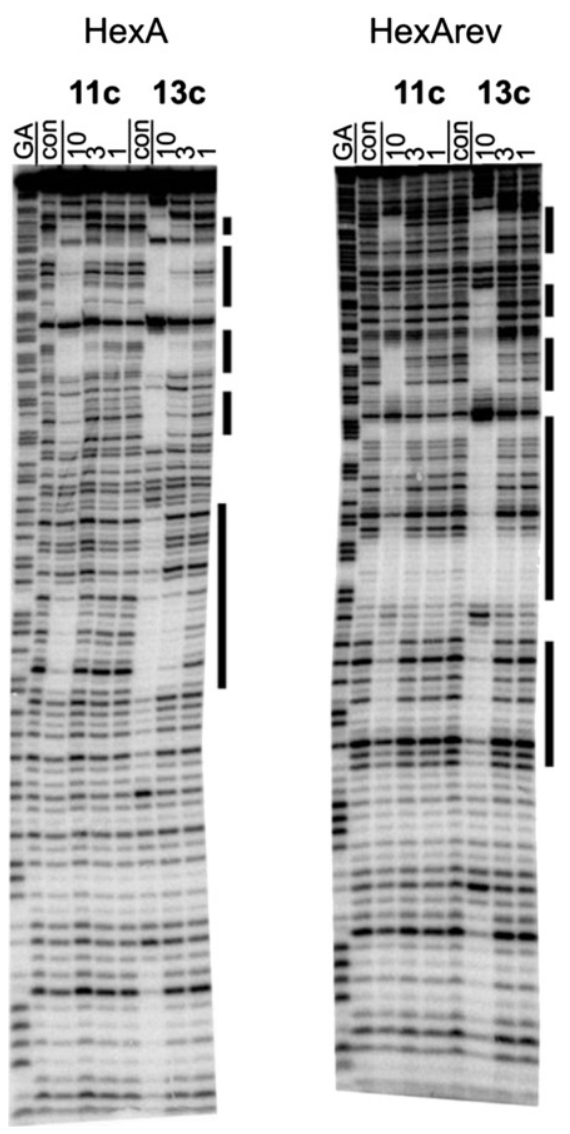

Fig. 1. DNase I digestion of the HexA and HexB fragments in the presence of (11c) and (13c). The DNA was labelled at the $3^{\prime}$-end so that the gel runs $3^{\prime}-5^{\prime}$ - from bottom to top. The ligand concentration $(\mu \mathrm{M})$ is shown at the top of each gel lane. Tracks labelled "con" are controls in the absence of added ligand while GA corresponds to a marker lane specific for purines. The sequence of the HexA fragment is shown in Figure KF2. The bars indicate the positions that are protected from cleavage by (13c).

the first examples of a new class of minor groove binder. The structural flexibility within this class has not yet been exploited but it can be readily appreciated that by changing the $N$-methyl group of the nitroalkene tail for other substituents, the properties of such compounds can readily be modified to include not only binding to DNA but also physicochemical properties that would be relevant to therapeutic applications.

\section{Experimental}

\subsection{DNase I footprinting}

DNase I footprinting was performed as previously described [9] using the HexA and HexRev DNA fragments [11-13]. These fragments which, contain the same sequence that has been inserted into the polylinker in opposite orientations, contain a selection of symmetrical hexanucleotide sequences and have previously been used for examining the interaction of several small ligands with DNA. The fragments were obtained by cutting the plasmids with HindIII and SacI and radiolabelling the $3^{\prime}$-end of the HindIII using $\alpha-{ }^{32} \mathrm{P}[\mathrm{dATP}] \mathrm{using}$ reverse transcriptase.

Footprinting was performed by mixing the radiolabelled DNA (dissolved in $10 \mathrm{mM}$ Tris- $\mathrm{HCl}$, pH 7.5 containing $0.1 \mathrm{mM}$ EDTA at a concentration of about $10 \mathrm{cps} / \mu \mathrm{l}(<10 \mathrm{nM}))$ with $1.5 \mu \mathrm{L}$ ligand (diluted in $10 \mathrm{mM}$ Tris- $\mathrm{HCl}, \mathrm{pH} 7.5$ containing $10 \mathrm{mM} \mathrm{NaCl}$ ). Samples were incubated for at least $30 \mathrm{~min}$ at room temperature, before adding $2 \mu \mathrm{L}$ DNase I (diluted in $20 \mathrm{mM} \mathrm{NaCl}, 2 \mathrm{mM} \mathrm{MgCl}$, $2 \mathrm{mM} \mathrm{MnCl}_{2}$ ) at a concentration of about 0.01 units $/ \mathrm{mL}$. The digestion was stopped after 1 min by adding $4.5 \mu \mathrm{L}$ of formamide containing $10 \mathrm{mM}$ EDTA and bromophenol blue. Samples were heated at $100{ }^{\circ} \mathrm{C}$ for 3 min before loading onto an $8 \%$ denaturing polyacrylamide gel containing $8 \mathrm{M}$ urea. After electrophoresis gels were fixed in $10 \%$ acetic acid, dried and exposed over night to a phosphorimaging screen.

\section{2. hERG evaluation [10]}

\subsubsection{Preparation of cells}

hERG transfected HEK293 cells were kindly gifted from Dr. J. Mitcheson, University of Leicester. Cell cultures were maintained in Gibco ${ }^{\circledR}$ Dulbecco's Modified Eagle Medium (D-MEM) + GlutaMAX$1^{\mathrm{TM}}$ medium supplemented with $10 \%$ foetal bovine serum (BSA), $1 \%$ penicillin-streptomycin and $0.8 \%$ Geneticin ${ }^{\circledR}$ in a Sanyo humidified incubator $\left(37{ }^{\circ} \mathrm{C}, 5 \% \mathrm{CO}_{2}\right)$. Once at $80-90 \%$ confluency, the cells were lifted using PBS based, enzyme free, Cell Dissociation Buffer.

HexA (top), HexARev (bottom)
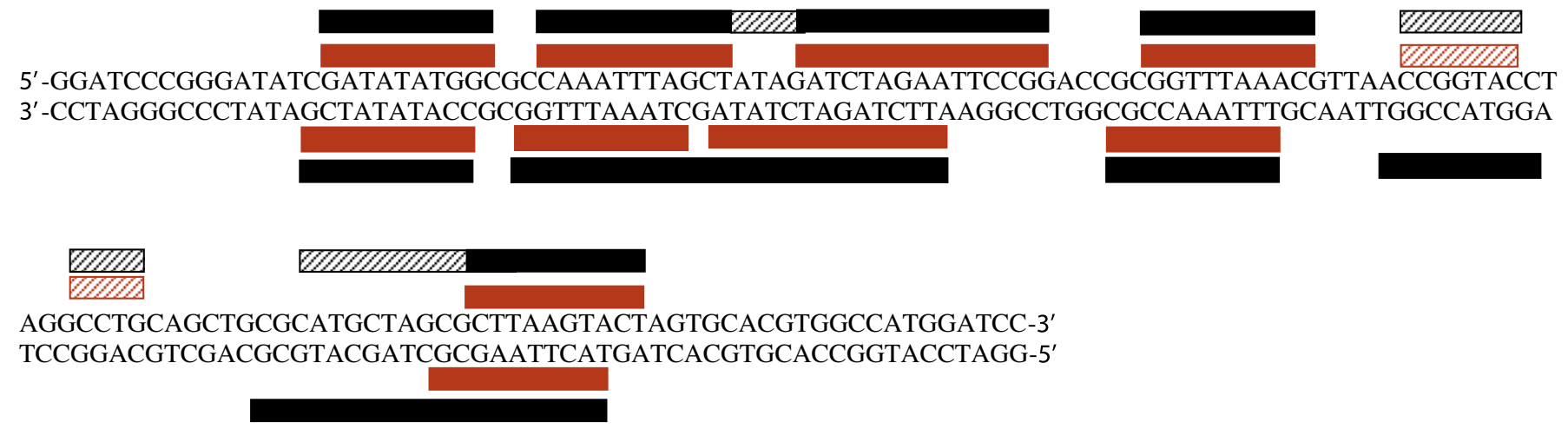

11c

13c

Fig. 2. Sequence of the HexA (top strand) and HexARev (lower strand), indicating the regions protected by 11c (black) and 13c (red). Hatched boxes show region that are only protected at the highest ligand concentration $(10 \mu \mathrm{M})$. (For interpretation of the references to colour in this figure legend, the reader is referred to the web version of this article.) 
The cell suspension was counted using a Bright Line Haemocytometer and centrifuged at $1000 \mathrm{rpm}$ for $5 \mathrm{~min}$ and the supernatant discarded. The pellet was resuspended in ice-cold Tris $\cdot \mathrm{HCl} \mathrm{pH} 7.4$ (20 mM) with 1\% phenylmethylsulfonyl fluoride (PMSF). The cells were homogenised using a Brinkman Polytron and the homogenate centrifuged using a Beckman Coulter Optima L-70K Ultracentrifuge or a L-100 XP Ultracentrifuge at $200,000 \mathrm{~g}$ for $40 \mathrm{~min}$ at $4{ }^{\circ} \mathrm{C}$, resuspended in buffer (10 mM HEPES, pH 7.4, $130 \mathrm{mM} \mathrm{NaCl}, 5 \mathrm{mM}$ $\mathrm{KCl}, 0.8 \mathrm{mM} \mathrm{MgCl}_{2}, 10 \mathrm{mM}$ glucose, $0.1 \% \mathrm{BSA}$ ), aliquots quick-frozen in liquid $\mathrm{N}_{2}$ and stored at $-80{ }^{\circ} \mathrm{C}$.

\subsection{2. hERG cell binding assay}

$\left[{ }^{3} \mathrm{H}\right]$-Astemizole binding in hERG transfected HEK293 cells were performed in $300 \mu \mathrm{L}$ total volume according to the following conditions: Cells ( 200,000 cells per assay tube, $100 \mu \mathrm{L}),\left[{ }^{3} \mathrm{H}\right]-$ astemizole $(0.5 \mathrm{nM}, 100 \mu \mathrm{L})$, incubation buffer (10 mM HEPES, $\mathrm{pH}$ 7.4, $130 \mathrm{mM} \mathrm{NaCl}, 5 \mathrm{mM} \mathrm{KCl}, 0.8 \mathrm{mM} \mathrm{MgCl}_{2}, 10 \mathrm{mM}$ glucose, $0.1 \%$ $\mathrm{BSA}, 100 \mu \mathrm{L})$ for total binding or drug compound $(10 \mu \mathrm{M}, 100 \mu \mathrm{L})$ for single point assay. Non-specific binding was determined using nonradiolabelled astemizole $(10 \mu \mathrm{M}, 100 \mu \mathrm{L})$. The tubes were incubated for $1 \mathrm{~h}$ at $30{ }^{\circ} \mathrm{C}$ after which time the tube contents were rapidly filtered using a Brandel Cell Harvester under vacuum, through GF/B filters and washed with ice-cold incubation buffer $(2 \mathrm{~mL} \times 5$, see above). The radioactivity retained on the filters (pre-soaked in $0.5 \%$ PEI) was measured by counting in scintillation fluid ( $4 \mathrm{~mL}$, Tri-Carb 1500 Packard; Emulsifier Safe).

\subsection{Synthesis}

\subsubsection{General experimental methods}

${ }^{1} \mathrm{H}$ and ${ }^{13} \mathrm{C}$ NMR spectra were measured on a Bruker DPX $400 \mathrm{MHz}$ spectrometer with chemical shifts given in ppm ( $\delta$ values), relative to proton and carbon traces in solvent. Coupling constants are reported in Hz. IR spectra were recorded on a Perkin Elmer, 1 FT-IR spectrometer. Elemental analysis was carried out on a Perkin Elmer 2400, analyser series 2. Mass spectra were obtained on a Jeol JMS AX505. Anhydrous solvents were obtained from a Puresolv purification system, from Innovative Technologies, or purchased as such from Aldrich. Melting points were recorded on a Reichert hot-stage microscope, and are uncorrected. Chromatography was carried out using 200-400 mesh silica gels, or using reverse-phase HPLC on a water system using a C18 Luna column with the gradient given in Table 2 .

\subsubsection{2-\{[(1-Methyl-4-nitro-1H-pyrrol-2-yl)carbonyl]amino\}ethyl acetate $(\mathbf{5 a})$ \\ $\mathrm{N}$-(2-Hydroxyethyl)-1-methyl-4-nitro-1H-pyrrole-2-} carboxamide $(0.826 \mathrm{~g}, 5.42 \mathrm{mmol})$ was dissolved in DCM $(10 \mathrm{~mL})$ and cooled to $0{ }^{\circ} \mathrm{C}$. Acetylchloride $(386 \mu \mathrm{L}, 5.42 \mathrm{mmol})$ in $\mathrm{DCM}$ $(2 \mathrm{~mL})$ was then added dropwise followed by triethylamine $(550 \mu \mathrm{L}$, $6.50 \mathrm{mmol}$ ) and the solution was allowed to return to room temperature over $2 \mathrm{~h}$. The solvent was then removed under reduced pressure and the residue purified by flash chromatography to give the title compound as an off-white solid (1.34 g, 97\%), Mp. $127-129^{\circ} \mathrm{C}$. IR $\nu_{\max }: 3410,3110,2952,1723,1661$ and $1308 \mathrm{~cm}^{-1} \cdot{ }^{1} \mathrm{H}$ NMR [DMSO- $d_{6}, 500 \mathrm{MHz}$ ]: $\delta_{\mathrm{H}} 2.01\left(3 \mathrm{H}, \mathrm{s}, \mathrm{CH}_{3}\right), 3.44\left(2 \mathrm{H}, \mathrm{q}, \mathrm{CH}_{2}\right.$,

Table 2

Programme for HPLC purification of minor groove binders.

\begin{tabular}{llll}
\hline Time/pump & A & B & Flow rate $(\mathrm{mL} / \mathrm{min})$ \\
\hline 0 & 90 & 10 & 6 \\
28 & 30 & 70 & 6 \\
33 & 10 & 90 & 6 \\
38 & 90 & 10 & 6 \\
40 & 90 & 10 & 0 \\
\hline
\end{tabular}

$J=5.7 \mathrm{~Hz}), 3.91\left(3 \mathrm{H}, \mathrm{s}, \mathrm{NCH}_{3}\right), 4.10\left(2 \mathrm{H}, \mathrm{t}, \mathrm{CH}_{2}, J=5.7 \mathrm{~Hz}\right), 7.43(1 \mathrm{H}$, $\mathrm{d}, \mathrm{Ar}-\mathrm{H}, J=2.0 \mathrm{~Hz}), 8.14(1 \mathrm{H}, \mathrm{d}, \mathrm{Ar}-\mathrm{H}, J=1.7 \mathrm{~Hz}), 8.54(1 \mathrm{H}, \mathrm{t}, \mathrm{NH}$, $J=6.5 \mathrm{~Hz}) .{ }^{13} \mathrm{C}$ NMR [DMSO- $\left.d_{6}, 100 \mathrm{MHz}\right]: \delta_{\mathrm{C}} 159.9,155.7,133,127.7$, 126.5, 107.4, 77.7, 37.2, 28.2. HRFABMS: Found: 256.0887 calculated for $\mathrm{C}_{10} \mathrm{H}_{14} \mathrm{~N}_{3} \mathrm{O}_{5}^{+}$256.0889. Anal. Calcd. For $\mathrm{C}_{10} \mathrm{H}_{13} \mathrm{~N}_{3} \mathrm{O}_{5}$ : C, 47.06; $\mathrm{H}$, 5.13; N, 16.46. Found: C, 47.13; H, 5.32; N, 16.16.

\subsection{3. tert-Butyl 2-\{[(1-methyl-4-nitro-1H-pyrrol-2-yl)carbonyl] amino\}ethylcarbamate (5b)}

2,2,2-Trichloro-1-(1-methyl-4-nitro-1H-pyrrol-2-yl)ethanone $(1.000 \mathrm{~g}, 3.70 \mathrm{mmol})$ was dissolved in DCM $(15 \mathrm{~mL})$, and a solution of $t$-butyl 2-aminoethylcarbamate $(584 \mu \mathrm{L}, 3.70 \mathrm{mmol})$ in $\mathrm{DCM}$ $(5 \mathrm{~mL})$ added. The solution was allowed to stir for $1 \mathrm{~h}$ after which the solvent was removed under reduced pressure to yield the title compound as an off-white solid (1.13 g, 98\%), Mp. 180-182 ${ }^{\circ} \mathrm{C}$. IR $\nu_{\max }: 3347,3126,2941,1686,1644,1329$ and $1274 \mathrm{~cm}^{-1} .{ }^{1} \mathrm{H}$ NMR [DMSO- $d_{6}, 400 \mathrm{MHz}$ ]: $\delta_{\mathrm{H}} 1.36\left(9 \mathrm{H}, \mathrm{s}, 3 \times \mathrm{CH}_{3}\right), 3.05\left(2 \mathrm{H}, \mathrm{q}, \mathrm{CH}_{2}\right.$, $J=6.1 \mathrm{~Hz}), 3.2\left(2 \mathrm{H}, \mathrm{q}, \mathrm{CH}_{2}, J=6.1 \mathrm{~Hz}\right), 3.88\left(3 \mathrm{H}, \mathrm{s}, \mathrm{NCH}_{3}\right), 6.89(1 \mathrm{H}, \mathrm{t}$, $\mathrm{NH}, J=5.6 \mathrm{~Hz}), 7.38(1 \mathrm{H}, \mathrm{d}, \mathrm{Ar}-\mathrm{H}, J=1.9 \mathrm{~Hz}), 8.11(1 \mathrm{H}, \mathrm{d}, \mathrm{Ar}-\mathrm{H}$, $J=1.9 \mathrm{~Hz}), 8.37(1 \mathrm{H}, \mathrm{t}, \mathrm{NH}, J=5.6 \mathrm{~Hz})$. LRMS: Found 313.1; calculated for $\mathrm{C}_{13} \mathrm{H}_{21} \mathrm{~N}_{4} \mathrm{O}_{5}+$ 313.1. Calcd. for $\mathrm{C}_{13} \mathrm{H}_{20} \mathrm{~N}_{4} \mathrm{O}_{5}$ : C, 49.99; $\mathrm{H}$, 6.45; N, 17.94; Found: C, 50.16; H, 6.20; N, 17.75.

\subsubsection{2-\{l(1-Methyl-4-\{I(1-methyl-4-nitro-1H-pyrrol-2-yl)} carbonyl Jamino\}-1H-pyrrol-2-yl)carbonyl Jamino\}ethyl acetate (6a)

2-\{[(1-Methyl-4-nitro-1H-pyrrol-2-yl)carbonyl]amino\}ethyl acetate (5a) $(0.900 \mathrm{~g}, 3.56 \mathrm{mmol})$ was dissolved in methanol $(10 \mathrm{~mL}), \mathrm{Pd} / \mathrm{C}(10 \%, 0.450 \mathrm{~g})$ was then added, the solution was then allowed to stir under hydrogen for $3 \mathrm{~h}$. The solution was then filtered and the solvent removed under reduced pressure. The residue was dissolved in DMF (1.5 mL) and added to a solution of 1-methyl-4nitro-1H-pyrrole-2-carbonyl chloride $(0.600 \mathrm{~g}, 3.56 \mathrm{mmol})$ and $\mathrm{N}$ methylmorpholine ( $431 \mu \mathrm{L}, 4.27 \mathrm{mmol})$, the solution was allowed to stir over night, during which time the product precipitated as a bright yellow solid which was collected by filtration $(0.860 \mathrm{~g}, 63 \%)$, Mp. 155-160 ${ }^{\circ} \mathrm{C}$. IR $\nu_{\max }: 3399,3296,3129,2957,1731,1657$ and $1303 \mathrm{~cm}^{-1}$. ${ }^{1} \mathrm{H}$ NMR (DMSO-d $6,400 \mathrm{MHz}$ ): $\delta_{\mathrm{H}} 2.01\left(3 \mathrm{H}, \mathrm{s}, \mathrm{CH}_{3}\right), 3.42$ $\left(2 \mathrm{H}, \mathrm{q}, \mathrm{CH}_{2}, J=5.8 \mathrm{~Hz}\right), 3.81\left(3 \mathrm{H}, \mathrm{s}, \mathrm{NCH}_{3}\right), 3.96\left(3 \mathrm{H}, \mathrm{s}, \mathrm{NCH}_{3}\right), 4.09$ $\left(2 \mathrm{H}, \mathrm{t}, \mathrm{CH}_{2}, J=5.8 \mathrm{~Hz}\right), 6.87(1 \mathrm{H}, \mathrm{d}, \mathrm{Ar}-\mathrm{H}, J=1.9 \mathrm{~Hz}), 7.23(1 \mathrm{H}, \mathrm{d}, \mathrm{Ar}-$ $\mathrm{H}, J=1.8 \mathrm{~Hz}), 7.58(1 \mathrm{H}, \mathrm{d}, \mathrm{Ar}-\mathrm{H}, J=2.0 \mathrm{~Hz}), 8.14(2 \mathrm{H}, \mathrm{m}, \mathrm{Ar}-\mathrm{H}$ and $\mathrm{NH}), 10.25(1 \mathrm{H}, \mathrm{s}, \mathrm{NH})$. LREIMS: Found 378.1365 calculated for $\mathrm{C}_{16} \mathrm{H}_{20} \mathrm{~N}_{5} \mathrm{O}_{6}^{+}$378.1369. Calcd. for $\mathrm{C}_{16} \mathrm{H}_{19} \mathrm{~N}_{5} \mathrm{O}_{6}$ : C, 50.93; $\mathrm{H}, 5.08 ; \mathrm{N}$, 18.56; Found: C, 50.47; H, 5.68; N, 18.21 .

4.3.5. tert-Butyl 2-\{[(1-methyl-4-\{[(1-methyl-4-nitro-1H-pyrrol-2-yl) carbonyl]amino\}-1H-pyrrol-2-yl)carbonyl]amino\}ethylcarbamate (6b)

2-\{[(1-Methyl-4-nitro-1H-pyrrol-2-yl)carbonyl]amino\}ethyl acetate (5a) $(0.500 \mathrm{~g}, 1.60 \mathrm{mmol})$ was dissolved in methanol $(10 \mathrm{~mL}), \mathrm{Pd} / \mathrm{C}(10 \%)(0.250 \mathrm{~g})$ was then added, the solution was then allowed to stir under hydrogen for $3 \mathrm{~h}$. The solution was then filtered and the solvent removed under reduced pressure. The residue was dissolved in DMF $(1.5 \mathrm{~mL})$ and added to a solution of 1-methyl-4-nitro-1H-pyrrole-2-carbonyl chloride $(0.272 \mathrm{~g}$, $1.60 \mathrm{mmol}$ ) and $\mathrm{N}$-methylmorpholine $(215 \mu \mathrm{L}, 2.10 \mathrm{mmol})$ in DCM $(10 \mathrm{~mL})$. The solution was allowed to stir over night, during which time the product precipitated as a pale yellow solid which was collected by filtration $(0.511 \mathrm{~g}, 72 \%), \mathrm{Mp} .>230{ }^{\circ} \mathrm{C}$. IR $\nu_{\max }$ : 3392 , $3143,2936,1683,1663,1632,1318$ and $1254 \mathrm{~cm}^{-1}$. ${ }^{1} \mathrm{H}$ NMR [DMSO$\left.d_{6}, 500 \mathrm{~Hz}\right]: \delta_{\mathrm{H}} 1.37\left(9 \mathrm{H}, \mathrm{s}, 3\left(\mathrm{CH}_{3}\right)\right), 3.05\left(2 \mathrm{H}, \mathrm{q}, \mathrm{CH}_{2}, J=6.1 \mathrm{~Hz}\right), 3.20$ $\left(2 \mathrm{H}, \mathrm{q}, \mathrm{CH}_{2}, J=6.1 \mathrm{~Hz}\right), 3.80\left(3 \mathrm{H}, \mathrm{s}, \mathrm{NCH}_{3}\right), 3.94\left(3 \mathrm{H}, \mathrm{s}, \mathrm{NCH}_{3}\right), 6.85$ $(2 \mathrm{H}, \mathrm{m}, \mathrm{NH}$ and $\mathrm{Ar}-\mathrm{H}), 7.20(1 \mathrm{H}, \mathrm{d}, \mathrm{Ar}-\mathrm{H}, J=1.9 \mathrm{~Hz}), 7.57(1 \mathrm{H}, \mathrm{d}$, $\mathrm{Ar}-\mathrm{H}, J=1.87 \mathrm{~Hz}), 8.01(1 \mathrm{H}, \mathrm{t}, \mathrm{NH}, J=5.51 \mathrm{~Hz}), 8.17(1 \mathrm{H}, \mathrm{d}, \mathrm{Ar}-\mathrm{H}$, $J=1.9 \mathrm{~Hz}), 10.23(1 \mathrm{H}, \mathrm{s}, \mathrm{NH}) .{ }^{13} \mathrm{C}$ NMR [DMSO- $\left.d_{6}, 100 \mathrm{MHz}\right]: \delta_{\mathrm{C}}$ $161.2,156.8,155.7,133.8,128.1,126.3,123.1,121.3,118.0,107.5,104.1$, 77.6, 45.5, 37.4, 35.9, 28.2. HRFABMS: Found 435.1945 calculated for 
$\mathrm{C}_{19} \mathrm{H}_{26} \mathrm{~N}_{6} \mathrm{O}_{6}^{+}$435.1947. Calculated for $\mathrm{C}_{19} \mathrm{H}_{25} \mathrm{~N}_{6} \mathrm{O}_{6}$ : C, 52.53; $\mathrm{H}, 6.03$; N, 19.34: Found: C, 51.98; H, 5.89; N, 19.57 .

4.3.6. tert-Butyl 2-[(\{4-[(\{4-[(\{6-[(E)-2-(4-methoxyphenyl)ethenyl]-3pyridinyl\}carbonyl)amino]-1-methyl-1H-pyrrol-2-yl\}carbonyl)amino]1-methyl-1H-pyrrol-2-yl\}carbonyl)amino]ethylcarbamate (8a)

tert-Butyl 2-\{[(1-methyl-4-\{[(1-methyl-4-nitro-1H-pyrrol-2-yl) carbonyl]amino\}-1H-pyrrol-2-yl)carbonyl]amino\}ethylcarbamate (6b) $(0.200 \mathrm{~g}, 0.46 \mathrm{mmol})$ was dissolved in methanol $(10 \mathrm{~mL})$ and cooled to $0{ }^{\circ} \mathrm{C} \mathrm{Pd} / \mathrm{C}(10 \%, 0.100 \mathrm{~g})$ was then added in small portions and the solution stirred under hydrogen for $3 \mathrm{~h}$. The solution was then filtered and the solvent removed under reduced pressure. The residue was dissolved anhydrous DMF (1 mL), 6-[(E)-2-(4methoxyphenyl)ethenyl]nicotinic acid (7a) $(0.117 \mathrm{~g}, 0.46 \mathrm{mmol})$ was then added along with HBTU $(0.350 \mathrm{~g}, 0.92 \mathrm{mmol})$ and 4methylmorpholine $(40 \mu \mathrm{L}, 0.46 \mathrm{mmol})$. The resulting solution was allowed to stir for $16 \mathrm{~h}$ before being purified by HPLC and the product fractions freeze dried to yield the title compound as an orange solid ( $45 \mathrm{mg}, 15 \%$ ), Mp. $>230^{\circ} \mathrm{C}$, purity by HPLC $=98 \%$. IR $\nu_{\text {max }}: 3446,3132,2925,1637,1594$ and $1260 \mathrm{~cm}^{-1}$. ${ }^{1} \mathrm{H}$ NMR (DMSO$\left.d_{6}, 400 \mathrm{~Hz}\right): \delta_{\mathrm{H}} 1.37(9 \mathrm{H}, \mathrm{s}, t-\mathrm{Bu}), 3.05\left(2 \mathrm{H}, \mathrm{m}, \mathrm{CH}_{2}\right), 3.19(2 \mathrm{H}, \mathrm{m}$, $\left.\mathrm{CH}_{2}\right), 3.82\left(6 \mathrm{H}, \mathrm{m}, \mathrm{NCH}_{3}\right.$ and $\left.\mathrm{OCH}_{3}\right), 3.87\left(3 \mathrm{H}, \mathrm{s}, \mathrm{NCH}_{3}\right), 6.88(3 \mathrm{H}, \mathrm{m}$, $\mathrm{Ar}-\mathrm{H}, \mathrm{NH}), 6.99(2 \mathrm{H}, \mathrm{d}, \mathrm{Ar}-\mathrm{H}, J=8.8 \mathrm{~Hz}), 7.08(1 \mathrm{H}, \mathrm{d}, \mathrm{Ar}-\mathrm{H}$, $J=1.8 \mathrm{~Hz}), 7.20(1 \mathrm{H}, \mathrm{d}, \mathrm{Ar}-\mathrm{H}, J=1.8 \mathrm{~Hz}), 7.25(1 \mathrm{H}, \mathrm{d},(\mathrm{C}=\mathrm{C}-\mathrm{H})$, $J=16.1 \mathrm{~Hz}), 7.35(1 \mathrm{H}, \mathrm{d}, \mathrm{Ar}-\mathrm{H}, J=1.8 \mathrm{~Hz}), 7.66(3 \mathrm{H}, \mathrm{m}, \mathrm{Ar}-\mathrm{H})$, $7.76(1 \mathrm{H}, \mathrm{d},(\mathrm{C}=\mathrm{C}-\mathrm{H}), J=16.1 \mathrm{~Hz}), 7.98(1 \mathrm{H}, \mathrm{t}, \mathrm{NH}, J=5.6 \mathrm{~Hz})$, $8.27(1 \mathrm{H}, \mathrm{d}$ of d, $\mathrm{Ar}-\mathrm{H}, J=2.2$ and $8.2 \mathrm{~Hz}), 9.06(1 \mathrm{H}, \mathrm{d}, \mathrm{Ar}-\mathrm{H}$, $J=2.2 \mathrm{~Hz}), 9.96(1 \mathrm{H}, \mathrm{s}, \mathrm{NH}), 10.50(1 \mathrm{H}, \mathrm{s}, \mathrm{NH})$. HRFABMS: Found: 642.2991; calculated for $\mathrm{C}_{34} \mathrm{H}_{40} \mathrm{~N}_{7} \mathrm{O}_{6}{ }^{+} 642.2995$.

4.3.7. tert-Butyl 2-(\{[4-(\{[4-(\{4-[(E)-2-(3-methoxyphenyl)ethenyl] benzoyl\}amino)-1-methyl-1H-pyrrol-2-yl]carbonyl\}amino)-1methyl-1H-pyrrol-2-yl]carbonyl\}amino)ethylcarbamate $(\boldsymbol{8 b})$

tert-Butyl 2-\{[(1-methyl-4-\{[(1-methyl-4-nitro-1H-pyrrol-2-yl) carbonyl]amino\}-1H-pyrrol-2-yl)carbonyl]amino\}ethylcarbamate 5a $(0.230 \mathrm{~g}, 0.529 \mathrm{mmol})$ was dissolved in methanol $(25 \mathrm{~mL})$ with stirring under nitrogen. The reaction mixture was cooled to $0{ }^{\circ} \mathrm{C}$ and $\mathrm{pd} / \mathrm{C}-10 \%$ (70 $\mathrm{mg}$ ) was added. The reaction mixture was hydrogenated for $4 \mathrm{~h}$ at room temperature and atmospheric pressure. The catalyst was removed over Kieselguhr and the solvent was removed under reduced pressure to give the amine as a brown glassy material which was used in the next step without further purification. The amine so formed was dissolved in DMF ( $5 \mathrm{~mL}$, dry) to which 2,3,4,5,6-pentafluorophenyl 4-[(E)-2-(3-methoxyphenyl)ethenyl] benzoate ( $240 \mathrm{mg}, 0.751 \mathrm{mmol}, 1.1$ molar equivalent) was added and the reaction mixture was heated at $55{ }^{\circ} \mathrm{C}$ for 3 days. Solvent was removed in vacuo and the residue was partitioned between (ethyl acetate/methanol 90/10) and potassium carbonate. The organic layer was collected after the extraction, dried $\left(\mathrm{Na}_{2} \mathrm{SO}_{4}\right)$ and the solvent was removed under reduced pressure. The crude product was triturated with a small amount of ethyl acetate and filtered. The required product ( $140 \mathrm{mg}, 41 \%$ ) was obtained as brown powder with no distinct melting point. IR $\nu_{\max }: 1695,1639,1584,1537,1397,1274$, $1169,1040,958,849$ and $776 \mathrm{~cm}^{-1} .{ }^{1} \mathrm{H}$ NMR [DMSO- $d_{6}, 400 \mathrm{~Hz}$ ]: $\delta_{\mathrm{H}}$ $10.34(1 \mathrm{H}, \mathrm{s}), 9.96(1 \mathrm{H}, \mathrm{s}), 7.99(3 \mathrm{H}, \mathrm{d}, J=8.5 \mathrm{~Hz}$ and $\mathrm{br} \mathrm{s}), 7.76(2 \mathrm{H}, \mathrm{d}$, $J=8.5 \mathrm{~Hz}), 7.38-7.31(4 \mathrm{H}, \mathrm{m}), 7.24-7.21(3 \mathrm{H}, \mathrm{m}), 7.10(1 \mathrm{H}, \mathrm{d}, 1.8 \mathrm{~Hz})$, 6.91-6.87 (3H, m), $3.89(3 \mathrm{H}, \mathrm{s}), 3.82(3 \mathrm{H}, \mathrm{s}), 3.81(3 \mathrm{H}, \mathrm{s}), 3.24(2 \mathrm{H}, \mathrm{q}$, $J=6.5 \mathrm{~Hz}), 3.09(2 \mathrm{H}, \mathrm{q}, J=6.5 \mathrm{~Hz}), 1.39(9 \mathrm{H}, \mathrm{s})$. HRESIMS: Found, 641.3081; calculated for $\mathrm{C}_{35} \mathrm{H}_{41} \mathrm{O}_{6} \mathrm{~N}_{6}, 641.3082$.

4.3.8. tert-Butyl 2-(\{[1-methyl-4-(\{[1-methyl-4-(\{4-[(E)-2-(3quinolinyl)ethenyl]benzoyl\}amino)-1H-pyrrol-2-yl]carbonyl\} amino)-1H-pyrrol-2-yl]carbonyl\}amino)ethylcarbamate (8c)

tert-Butyl 2-\{[(1-methyl-4-\{[(1-methyl-4-nitro-1H-pyrrol-2-yl) carbonyl]amino\}-1H-pyrrol-2-yl)carbonyl]amino\}ethylcarbamate (6b) (0.200 g, $0.46 \mathrm{mmol})$ was taken up in methanol $(10 \mathrm{~mL})$ and cooled to $0{ }^{\circ} \mathrm{C} \mathrm{Pd} / \mathrm{C}(10 \%, 0.100 \mathrm{~g})$ was then added in small portions and the solution stirred under hydrogen for $3 \mathrm{~h}$. The solution was then filtered and the solvent removed under reduced pressure. The residue was dissolved in anhydrous DMF $(1 \mathrm{~mL}), 4-[(E)-2-(3-$ quinolinyl)ethenyl]benzoic acid $(0.126 \mathrm{~g}, 0.46 \mathrm{mmol})$ was then added along with HBTU $(0.350 \mathrm{~g}, 0.92 \mathrm{mmol})$ and 4methylmorpholine ( $40 \mu \mathrm{L}, 0.46 \mathrm{mmol}$ ). The resulting solution was allowed to stir for $16 \mathrm{~h}$ before being purified by HPLC and the product fractions freeze dried to yield the product as a yellow solid (84 mg, $25 \%$ ) Mp. $>230{ }^{\circ} \mathrm{C}$, purity by HPLC $=98 \%$. IR $\nu_{\max }: 3420$, 3066, 2922, 1658, 1578 and $1393 \mathrm{~cm}^{-1} .{ }^{1} \mathrm{H}$ NMR (DMSO-d $\left.d_{6}\right): 1.38$ $(9 \mathrm{H}, \mathrm{s}), 3.06(2 \mathrm{H}, \mathrm{m}), 3.20(2 \mathrm{H}, \mathrm{m}), 3.80(3 \mathrm{H}, \mathrm{s}), 3.87(3 \mathrm{H}, \mathrm{s}), 6.87(2 \mathrm{H}$, m) $7.09(1 \mathrm{H}, \mathrm{d}, J=1.7 \mathrm{~Hz}), 7.19(1 \mathrm{H}, \mathrm{d}, J=1.7 \mathrm{~Hz}), 7.35(1 \mathrm{H}, \mathrm{d}$, $J=1.7 \mathrm{~Hz}), 7.49(1 \mathrm{H}, \mathrm{d}, J=16.5 \mathrm{~Hz}), 7.64(4 \mathrm{H}, \mathrm{m}), 7.81(4 \mathrm{H}, \mathrm{m}), 8.02$ $(2 \mathrm{H}, \mathrm{m}), 8.63(1 \mathrm{H}, \mathrm{d}, J=1.9 \mathrm{~Hz}), 9.24(1 \mathrm{H}, \mathrm{d}, J=2.1 \mathrm{~Hz}), 9.94(1 \mathrm{H}, \mathrm{s})$, $10.39(1 \mathrm{H}, \mathrm{s})$. LRMS: Found, $662.13(\mathrm{M}+1)$; calculated for $\mathrm{C}_{37} \mathrm{H}_{39} \mathrm{~N}_{7} \mathrm{O}_{5}{ }^{+}, 661.30$.

\subsubsection{2-[(\{4-[(\{4-[(\{6-[(E)-2-(4-Methoxyphenyl)ethenyl]-3-} pyridinyl\}carbonyl)amino]-1-methyl-1H-pyrrol-2-yl\}carbonyl) amino]-1-methyl-1H-pyrrol-2-yl\}carbonyl)amino]ethyl acetate (9a)

6-[(E)-2-(4-Methoxyphenyl)ethenyl]nicotinic acid (7a) $0.067 \mathrm{~g}$, $0.27 \mathrm{mmol})$ was dissolved in DCM $(2 \mathrm{~mL})$ and thionyl chloride $(5 \mathrm{~mL})$ added and the solution refluxed for $1 \mathrm{~h}$, after which the solvent was removed under reduced pressure to give 6[(E)-2-(4-methoxyphenyl)ethenyl]nicotinoyl chloride as a dark orange solid. 2-\{[(1-Methyl-4-\{[(1-methyl-4-nitro-1H-pyrrol-2-yl) carbonyl]amino - $1 H$-pyrrol-2-yl)carbonyl]amino\}ethyl acetate (6a) $(0.100 \mathrm{~g}, 0.27 \mathrm{mmol})$ was dissolved in methanol $(5 \mathrm{~mL}), \mathrm{Pd} / \mathrm{C}$, $(10 \%, 0.050 \mathrm{~g})$ was then added, the solution was then allowed to stir under hydrogen for $3 \mathrm{~h}$, the solution was then filtered and the solvent removed under vacuum, the residue was dissolved in DMF $(1.5 \mathrm{~mL})$ and added to the previously prepared $6-[(E)-2-(4-$ methoxyphenyl)ethenyl]nicotinoyl chloride, and $\mathrm{N}$-methylmorpholine ( $36 \mu \mathrm{L}, 0.32 \mathrm{mmol}$ ) added and the solution allowed to stir over night, the solution was then purified by HPLC to give the title compound as an orange solid ( $40 \mathrm{mg}, 27 \%$ ), Mp. $>230^{\circ} \mathrm{C}$, purity by $\mathrm{HPLC}=97 \%$. IR $\nu_{\max }$ : 3446, 2925, 1637, 1594 and $1260 \mathrm{~cm}^{-1} .{ }^{1} \mathrm{H}$ NMR [DMSO- $d_{6}, 400 \mathrm{~Hz}$ ]: $\delta_{\mathrm{H}} 2.02\left(3 \mathrm{H}, \mathrm{s}, \mathrm{CH}_{3}\right), 3.40\left(2 \mathrm{H}, \mathrm{q}, \mathrm{CH}_{2}\right.$, $J=5.7 \mathrm{~Hz}), 3.81\left(6 \mathrm{H}, \mathrm{m}, \mathrm{NCH}_{3}\right.$ and $\left.\mathrm{OCH}_{3}\right), 3.88\left(3 \mathrm{H}, \mathrm{s}, \mathrm{NCH}_{3}\right), 4.09$ $\left(2 \mathrm{H}, \mathrm{t}, \mathrm{CH}_{2}, J=5.7 \mathrm{~Hz}\right), 6.89(1 \mathrm{H}, \mathrm{d}, \mathrm{Ar}-\mathrm{H}, J=1.8 \mathrm{~Hz}), 7.00(2 \mathrm{H}, \mathrm{d}$, $\mathrm{Ar}-\mathrm{H}, J=8.8 \mathrm{~Hz}), 7.10(1 \mathrm{H}, \mathrm{d}, \mathrm{Ar}-\mathrm{H}, J=1.8 \mathrm{~Hz}), 7.23(1 \mathrm{H}, \mathrm{d}, \mathrm{Ar}-\mathrm{H}$, $J=1.8 \mathrm{~Hz}), 7.26(1 \mathrm{H}, \mathrm{d},(\mathrm{C}=\mathrm{C}-\mathrm{H}), J=16.1 \mathrm{~Hz}), 7.37(1 \mathrm{H}, \mathrm{d}, \mathrm{Ar}-\mathrm{H}$, $J=1.8 \mathrm{~Hz}), 7.66(3 \mathrm{H}, \mathrm{m}, \mathrm{Ar}-\mathrm{H}), 7.77(1 \mathrm{H}, \mathrm{d}, \quad(\mathrm{C}=\mathrm{C}-\mathrm{H})$, $J=16.1 \mathrm{~Hz}), 8.14(1 \mathrm{H}, \mathrm{t}, \mathrm{NH}, J=5.6 \mathrm{~Hz}), 8.29(1 \mathrm{H}, \mathrm{d}$ of $\mathrm{d}, \mathrm{Ar}-\mathrm{H}$, $J=2.3$ and $8.2 \mathrm{~Hz}), 9.07(1 \mathrm{H}, \mathrm{d}, \mathrm{Ar}-\mathrm{H}, J=2.2 \mathrm{~Hz}), 9.98(1 \mathrm{H}, \mathrm{s}$, $\mathrm{NH}), 10.51(1 \mathrm{H}, \mathrm{s}, \mathrm{NH})$. HRMS: Found, 585.2419; calculated for $\mathrm{C}_{31} \mathrm{H}_{33} \mathrm{~N}_{6} \mathrm{O}_{6}+585.2417$.

\subsubsection{2-(\{[4-(\{[4-(\{4-[(E)-2-(3-Methoxyphenyl)ethenyl]benzoyl $\}$} amino)-1-methyl-1H-pyrrol-2-yl]carbonyl\}amino)-1-methyl-1Hpyrrol-2-yl]carbonyl\}amino)ethyl acetate $(\mathbf{9 b})$

2-\{[(1-Methyl-4-\{[(1-methyl-4-nitro-1H-pyrrol-2-yl)carbonyl] amino\}-1H-pyrrol-2-yl)carbonyl]amino\}ethyl acetate $(25 \mathrm{mg}$, $0.07 \mathrm{mmol})$ was dissolved in methanol $(25 \mathrm{~mL})$ with stirring under nitrogen. The reaction mixture was cooled to $0{ }^{\circ} \mathrm{C}$ and $\mathrm{Pd} / \mathrm{C}-10 \%$ (15 mg) was added. The reaction mixture was hydrogenated for $2 \mathrm{~h}$ at room temperature and atmospheric pressure. The catalyst was removed over Kieselguhr and the solvent was removed under reduced pressure to give the amine which was used in the next step without further purification. The amine so formed was dissolved in DMF (3 mL, dry) to which 2,3,4,5,6-pentafluorophenyl 4-[(E)-2-(3methoxyphenyl)ethenyl]benzoate (56 $\mathrm{mg}, 0.13 \mathrm{mmol}$ ) was added and the reaction mixture was heated at $50{ }^{\circ} \mathrm{C}$ for 2 days. Solvent 
was removed in vacuo and the residue was partitioned between ethyl acetate and sodium hydrogen carbonate. The organic layer was collected after the extraction, dried and the solvent removed. The crude product was purified by column chromatography using ethyl acetate $/ n$-hexane $\left(2 / 1, R_{F}=0.1\right)$. The required product ( $22 \mathrm{mg}$, $54 \%$ ) was obtained as a pale yellow solid with no distinct melting point. IR $\nu_{\max }$ : 1741, 1638, 1583, 1540, 1515, 1469, 1437, 1394, 1242 1043 and $776 \mathrm{~cm}^{-1} .{ }^{1} \mathrm{H}$ NMR [DMSO- $d_{6}, 400 \mathrm{~Hz}$ ]: $\delta_{\mathrm{H}} 10.31(1 \mathrm{H}, \mathrm{s})$, $9.94(1 \mathrm{H}, \mathrm{s}), 8.12(1 \mathrm{H}, \mathrm{t}, J=5.5 \mathrm{~Hz}), 7.97(2 \mathrm{H}, \mathrm{d}, J=8.5 \mathrm{~Hz}), 7.74(2 \mathrm{H}$, $\mathrm{d}, J=8.5 \mathrm{~Hz}), 7.36-7.30(4 \mathrm{H}, \mathrm{m}), 7.22-7.21(3 \mathrm{H}, \mathrm{m}), 7.10(1 \mathrm{H}, \mathrm{d}$, $J=1.8 \mathrm{~Hz}), 6.89-6.87(2 \mathrm{H}, \mathrm{m}), 4.10(2 \mathrm{H}, \mathrm{t}, J=5.8 \mathrm{~Hz}), 3.87(3 \mathrm{H}, \mathrm{s})$, $3.81(3 \mathrm{H}, \mathrm{s}), 3.80(3 \mathrm{H}, \mathrm{s}), 3.42-3.24(2 \mathrm{H}, \mathrm{q}, J=5.8 \mathrm{~Hz}), 2.01(3 \mathrm{H}, \mathrm{s})$. HRESIMS: Found: 584.2499; calculated for $\mathrm{C}_{32} \mathrm{H}_{34} \mathrm{O}_{6} \mathrm{~N}_{5}, 584.2504$.

\subsubsection{1. $\mathrm{N}-(5-\{[(2-$ Aminoethyl)amino $]$ carbonyl $\}-1-$ methyl-1H-} pyrrol-3-yl)-4-(\{4-[(E)-2-(3-methoxyphenyl)ethenyl]benzoyl $\}$ amino)-1-methyl-1H-pyrrole-2-carboxamide (10b)

tert-Butyl 2-(\{[4-(\{[4-(\{4-[(E)-2-(3-methoxyphenyl)ethenyl] benzoyl \}amino)-1-methyl-1H-pyrrol-2-yl]carbonyl \}amino)-1-met hyl-1H-pyrrol-2-yl]carbonyl \}amino)ethylcarbamate $(\mathbf{8 b})(20 \mathrm{mg}$, $0.03 \mathrm{mmol}$ ) was dissolved in dichloromethane ( $4 \mathrm{~mL}$, dry) to which was added trifluoroacetic acid $(0.5 \mathrm{~mL})$. The reaction mixture was heated under reflux for $30 \mathrm{~min}$. Excess trifluoroacetic acid and dichloromethane were removed under reduced pressure to give the protonated amine as light brown solid in quantitative yield with no distinct melting point. IR $\nu_{\max }$ : 1779, 1641, 1587, 1535, 1438, 1404, $1274,1166,1050,962,810,781$ and $703 \mathrm{~cm}^{-1} .{ }^{1} \mathrm{H}$ NMR [DMSO-d $d_{6}$, $400 \mathrm{~Hz}$ : $\delta_{\mathrm{H}} 10.32(1 \mathrm{H}, \mathrm{s}), 9.97(1 \mathrm{H}, \mathrm{s}), 8.13(1 \mathrm{H}, \mathrm{t}, J=5.5 \mathrm{~Hz}), 7.99$ $(2 \mathrm{H}, \mathrm{d}, J=8.5 \mathrm{~Hz}), 7.76(2 \mathrm{H}, \mathrm{d}, J=8.5 \mathrm{~Hz}), 7.37-7.31(4 \mathrm{H}, \mathrm{m}), 7.24-$ $7.22(2 \mathrm{H}, \mathrm{m}), 7.21(1 \mathrm{H}, \mathrm{d}, 1.8 \mathrm{~Hz}), 7.13(1 \mathrm{H}, \mathrm{d}, J=1.8 \mathrm{~Hz}), 6.99(1 \mathrm{H}, \mathrm{d}$, $J=1.8 \mathrm{~Hz}), 6.91-6.88(1 \mathrm{H}, \mathrm{m}), 3.88(3 \mathrm{H}, \mathrm{s}), 3.84(3 \mathrm{H}, \mathrm{s}), 3.82(3 \mathrm{H}, \mathrm{s})$, $3.45(2 \mathrm{H}, \mathrm{q}, J=6.0 \mathrm{~Hz}), 2.98(2 \mathrm{H}, \mathrm{qt}, J=6.0 \mathrm{~Hz})$. HRESIMS: Found: 541.2556; calculated for $\mathrm{C}_{30} \mathrm{H}_{33} \mathrm{O}_{4} \mathrm{~N}_{6}, 541.2558$.

4.3.12. 3-[(E)-2-(4-\{[(5-\{[(5-\{[(2-Ammonioethyl)amino $]$ carbonyl $\}-1-$ methyl-1H-pyrrol-3-yl)amino]carbonyl\}-1-methyl-1H-pyrrol-3-yl) amino]carbonyl\}phenyl)ethenyl]quinolinium bis(trifluoroacetate)(10c)

tert-Butyl 2-(\{[1-methyl-4-(\{[1-methyl-4-(\{4-[(E)-2-(3-quinolinyl) ethenyl]benzoyl \}amino)-1H-pyrrol-2-yl]carbonyl\}amino)-1H-pyrrol2-yl]carbonyl \}amino)ethylcarbamate (8c) $(20 \mathrm{mg}, 0.03 \mathrm{mmol})$ was dissolved in $\mathrm{DCM}(2 \mathrm{~mL})$ to which was added trifluoroacetic acid $(1 \mathrm{~mL})$ and this was heated to $40{ }^{\circ} \mathrm{C}$ for $1 \mathrm{~h}$. After this, the solvents were removed under reduced pressure. The resultant residue was dissolved in DMF ( $1 \mathrm{~mL}$ ) and subjected to HPLC purification to obtain the desired product ( $24 \mathrm{mg}, 99 \%$ yield), with no distinct melting point. IR $\nu_{\max }$ : 3424, 2928, 2857, 1677, 1641, 1580, 1465, 1436, 1405, 1203, 1133, 837, 773 and $722 \mathrm{~cm}^{-1} .{ }^{1} \mathrm{H}$ NMR [DMSO- $d_{6}, 400 \mathrm{~Hz}$ ]: $\delta_{\mathrm{H}} 10.35(1 \mathrm{H}, \mathrm{s}), 9.96$ $(1 \mathrm{H}, \mathrm{s}), 9.26(1 \mathrm{H}, \mathrm{d}, J=2.0 \mathrm{~Hz}), 8.55(1 \mathrm{H}, \mathrm{d}, J=2.0 \mathrm{~Hz}), 8.11(1 \mathrm{H}, \mathrm{t}$, $J=6.0 \mathrm{~Hz}), 7.98-8.04(4 \mathrm{H}, \mathrm{m}), 7.81(2 \mathrm{H}, \mathrm{d}, J=9.0 \mathrm{~Hz}), 7.59-7.77(8 \mathrm{H}$, $\mathrm{m}), 7.34(1 \mathrm{H}, \mathrm{d}, J=2.0 \mathrm{~Hz}), 7.19(1 \mathrm{H}, \mathrm{d}, J=2.0 \mathrm{~Hz}), 7.12(1 \mathrm{H}, \mathrm{d}, J=2.0 \mathrm{~Hz})$, $6.98(1 \mathrm{H}, \mathrm{d}, J=2.0 \mathrm{~Hz}), 3.87(3 \mathrm{H}, \mathrm{s}), 3.82(3 \mathrm{H}, \mathrm{s}), 3.14(2 \mathrm{H}, \mathrm{q}, J=6.0 \mathrm{~Hz})$, 2.92-2.97 (2H, m). HRESIMS: Found, 562.2559; calculated for $\mathrm{C}_{32} \mathrm{H}_{32} \mathrm{O}_{3} \mathrm{~N}_{7}, 562.2561$.

4.3.13. 6-[(E)-2-(4-Methoxyphenyl)ethenyl]-N-(1-methyl-5-\{[(1methyl-5-\{[(2-\{[(E)-1-(methylamino)-2-nitroethenyl ]amino\}ethyl) amino]carbonyl\}-1H-pyrrol-3-yl)amino]carbonyl\}-1H-pyrrol-3-yl) nicotinamide (11a)

tert-Butyl 2-[(\{4-[(\{4-[(\{6-[(E)-2-(4-methoxyphenyl)ethenyl]-3pyridinyl\}carbonyl) amino]-1-methyl-1H-pyrrol-2-yl\}carbonyl) amino]-1-methyl-1H-pyrrol-2-yl carbonyl)amino]ethylcarbamate (8a) $(0.020 \mathrm{~g}, 0.03 \mathrm{mmol})$ was dissolved in DCM $(3 \mathrm{~mL})$ and trifluoroacetic acid $(3 \mathrm{~mL})$ and the solution refluxed for $30 \mathrm{~min}$. The solvents where then removed under reduced pressure to yield the amine salt. This was then dissolved in $80 \%$ aqueous ethanol ( $3 \mathrm{~mL}$ ), potassium carbonate $(0.016 \mathrm{~g}, 0.06 \mathrm{mmol})$ is then added followed by methyl-(1-methylsulfanyl-2-nitro-vinyl)-amine $(0.015 \mathrm{~g}$, $0.06 \mathrm{mmol}$ ) the solution was then refluxed over night. The solution was then allowed to cool to room temperature before removing the solvent under reduced pressure; the residue was then dissolved in DMF and purified by HPLC to yield the desired product as a yellow/ orange solid ( $4 \mathrm{mg}, 21 \%$ ), Mp. $>230{ }^{\circ} \mathrm{C}$, purity by HPLC $=98 \%$. IR $\nu_{\max }: 3438,3137,2908,1628,1530$ and $1353 \mathrm{~cm}^{-1}$. ${ }^{1} \mathrm{H}$ NMR (DMSO$\left.d_{6}, 400 \mathrm{~Hz}\right): \delta_{\mathrm{H}} 2.38\left(3 \mathrm{H}, \mathrm{s}, \mathrm{CH}_{3}\right), 3.75\left(2 \mathrm{H}, \mathrm{m}, \mathrm{CH}_{2}\right), 2.96(2 \mathrm{H}, \mathrm{m}$, $\left.\mathrm{CH}_{2}\right), 3.84\left(6 \mathrm{H}, \mathrm{m}, \mathrm{NCH}_{3}\right.$ and $\left.\mathrm{OCH}_{3}\right), 3.89\left(3 \mathrm{H}, \mathrm{s}, \mathrm{NCH}_{3}\right), 6.86(3 \mathrm{H}, \mathrm{m}$, $\mathrm{Ar}-\mathrm{H}, \mathrm{NH}), 7.01(2 \mathrm{H}, \mathrm{d}, \mathrm{Ar}-\mathrm{H}, J=8.8 \mathrm{~Hz}), 7.10(1 \mathrm{H}, \mathrm{d}, \mathrm{Ar}-\mathrm{H}$, $J=1.8 \mathrm{~Hz}), 7.21(1 \mathrm{H}, \mathrm{d}, \mathrm{Ar}-\mathrm{H}, J=1.8 \mathrm{~Hz}), 7.27(1 \mathrm{H}, \mathrm{d},(\mathrm{C}=\mathrm{C}-\mathrm{H})$, $J=16.1 \mathrm{~Hz}), 7.33(1 \mathrm{H}, \mathrm{d}, \mathrm{Ar}-\mathrm{H}, J=1.8 \mathrm{~Hz}), 7.66(3 \mathrm{H}, \mathrm{m}, \mathrm{Ar}-\mathrm{H})$, $7.75(1 \mathrm{H}, \mathrm{d},(\mathrm{C}=\mathrm{C}-\mathrm{H}), J=16.1 \mathrm{~Hz}), 7.98(1 \mathrm{H}, \mathrm{t}, \mathrm{NH}, J=5.6 \mathrm{~Hz})$, $8.25(1 \mathrm{H}, \mathrm{d}$ of d, $\mathrm{Ar}-\mathrm{H}, J=2.3$ and $8.2 \mathrm{~Hz}), 9.06(1 \mathrm{H}, \mathrm{d}, \mathrm{Ar}-\mathrm{H}$, $J=2.2 \mathrm{~Hz}), 9.98(1 \mathrm{H}, \mathrm{s}, \mathrm{NH}), 10.50(1 \mathrm{H}, \mathrm{s}, \mathrm{NH})$. HRFABMS: Found: 642.2743; calculated for $\mathrm{C}_{34} \mathrm{H}_{36} \mathrm{~N}_{9} \mathrm{O}_{6}{ }^{+}$642.2744.

4.3.14. 4-(\{4-[(E)-2-(3-Methoxyphenyl)ethenyl]benzoyl\}amino)-1methyl-N-(1-methyl-5-\{[(2-\{[(E)-1-(methylamino)-2-nitroethenyl $]$ amino\}ethyl)amino]carbonyl\}-1H-pyrrol-3-yl)-1H-pyrrole-2carboxamide (11b)

$N$-(5-\{[(2-Aminoethyl)amino]carbonyl $\}-1-m e t h y l-1 H$-pyrrol-3yl)-4-(\{4-[(E)-2-(3-methoxyphenyl)ethenyl]benzoyl \}amino)-1-meth yl-1H-pyrrole-2-carboxamide (10b) (16 $\mathrm{mg}, 0.03 \mathrm{mmol}$ ) was dissolved in ethanol $(4 \mathrm{~mL})$ to which potassium carbonate $(20 \mathrm{mg}$, $0.14 \mathrm{mmol}$ ) and $(E)-N$-methyl-1-(methylsulfanyl)-2-nitroethenamine (22 $\mathrm{mg}, 0.14 \mathrm{mmol}$ ) were added and the reaction mixture was heated under refluxed for $48 \mathrm{~h}$ under nitrogen. The solvent was removed under reduced pressure to give the crude product which was purified by HPLC. Fractions containing the required material were collected and freeze-dried to give the desired product as a pale yellow solid (4 mg, 21\%) with no distinct melting point. IR $\nu_{\max }$ : 1641, 1575, 1534, 1436, 1266, 1200, 1155, 1052 and $779 \mathrm{~cm}^{-1} .{ }^{1} \mathrm{H}$ NMR [DMSO- $d_{6}$, $400 \mathrm{~Hz}$ ]: $\delta_{\mathrm{H}} 10.35(1 \mathrm{H}, \mathrm{s}), 9.99(1 \mathrm{H}, \mathrm{s}), 8.24(1 \mathrm{H}, \mathrm{t}, J=5.5 \mathrm{~Hz}), 7.99(2 \mathrm{H}$, $\mathrm{d}, J=8.5 \mathrm{~Hz}), 7.76(2 \mathrm{H}, \mathrm{d}, J=8.5 \mathrm{~Hz}), 7.38-7.31(4 \mathrm{H}, \mathrm{m}), 7.23-7.22(3 \mathrm{H}$, $\mathrm{m}), 7.10(1 \mathrm{H}, \mathrm{d}, J=1.8 \mathrm{~Hz}), 6.92-6.88(2 \mathrm{H}, \mathrm{m}), 3.88(3 \mathrm{H}, \mathrm{s}), 3.45-3.24$ $(4 \mathrm{H}, \mathrm{m}), 2.87(3 \mathrm{H})$. HRESIMS: Found: 641.2834; calculated for $\mathrm{C}_{33} \mathrm{H}_{37} \mathrm{O}_{6} \mathrm{~N}_{8}$ 641.2831.

4.3.15. 1-Methyl-N-(1-methyl-5-\{I(2-\{I(E)-1-(methylamino)-2nitroethenyl]amino\}ethyl)amino]carbonyl\}-1H-pyrrol-3-yl)-4(\{4-[(E)-2-(3-quinolinyl)ethenyl]benzoyl\}amino)-1H-pyrrole-2carboxamide trifluoroacetate (11c)

This material was prepared using an analogous procedure to that for (11a) from (8c) as an orange solid in (28 mg, $23 \%$ ), Mp. $>230^{\circ} \mathrm{C}$, purity by HPLC $=98 \%$. IR $\nu_{\max }: 3414,3072,2926,1660,1570$ and $1384 \mathrm{~cm}^{-1}$. ${ }^{1} \mathrm{H}$ NMR [DMSO-d $6,500 \mathrm{~Hz}$ ]: $\delta_{\mathrm{H}} 2.58$ (3H, s, N-Me), 3.28 $\left(2 \mathrm{H}, \mathrm{m}, \mathrm{CH}_{2}\right), 3.33\left(2 \mathrm{H}, \mathrm{m}, \mathrm{CH}_{2}\right), 3.91(1 \mathrm{H}, \mathrm{s}, \mathrm{C}=\mathrm{C}-\mathrm{H}), 3.92(3 \mathrm{H}, \mathrm{s}, \mathrm{N}-$ $\mathrm{Me}), 3.96(3 \mathrm{H}, \mathrm{s}, \mathrm{N}-\mathrm{Me}), 7.08(1 \mathrm{H}, \mathrm{d}, \mathrm{Ar}-\mathrm{H}, J=1.7 \mathrm{~Hz}), 7.21(1 \mathrm{H}, \mathrm{d}$, $\mathrm{Ar}-\mathrm{H}, J=1.7 \mathrm{~Hz}), 7.38(1 \mathrm{H}, \mathrm{d}, \mathrm{Ar}-\mathrm{H}, J=1.7 \mathrm{~Hz}), 7.49(1 \mathrm{H}, \mathrm{d}, \mathrm{C}=\mathrm{C}-\mathrm{H}$, $J=16.5 \mathrm{~Hz}), 7.64(4 \mathrm{H}, \mathrm{m}, \mathrm{Ar}-\mathrm{H}), 7.81(3 \mathrm{H}, \mathrm{m}, \mathrm{Ar}-\mathrm{H}), 8.02(2 \mathrm{H}, \mathrm{m}$, $\mathrm{Ar}-\mathrm{H}), 8.63(1 \mathrm{H}, \mathrm{d}, \mathrm{Ar}-\mathrm{H}, J=1.9 \mathrm{~Hz}), 9.24(1 \mathrm{H}, \mathrm{d}, \mathrm{Ar}-\mathrm{H}, J=2.1 \mathrm{~Hz})$, $9.96(1 \mathrm{H}, \mathrm{s}, \mathrm{N}-\mathrm{H}), 10.36(1 \mathrm{H}, \mathrm{d}, \mathrm{N}-\mathrm{H})$. [DMSO- $d_{6}, 500 \mathrm{~Hz}$ ]: $\delta_{\mathrm{C}} 163.7$, $162.4,158.9,158.8,158.5,149.6,149.5,146.5,139.9,134.3,133.9$, 133.8, 130.6, 130.5, 128.8, 128.4127.9, 127.3, 127.0, 123.4, 122.9, 122.7, $119.3,118.7,117.5,115.5,105.4,105.3$. LRMS: Found: 662.13 calculated for $\mathrm{C}_{35} \mathrm{H}_{36} \mathrm{~N}_{9} \mathrm{O}_{5}{ }^{+}, 662.28$.

4.3.16. $N-(5-\{[(2-\{[(E)-($ Cyanoimino $)(m e t h y l a m i n o) m e t h y l] a m i n o\}$ ethyl)amino]carbonyl\}-1-methyl-1H-pyrrol-3-yl)-1-methyl-4-(\{4[(E)-2-(3-quinolinyl)ethenyl]benzoyl\}amino)-1H-pyrrole-2-

carboxamide trifluoroacetate $(\mathbf{1 2 c})$

tert-Butyl 2-(\{[1-methyl-4-(\{[1-methyl-4-(\{4-[(E)-2-(3-quinolinyl) ethenyl]benzoyl \}amino)-1H-pyrrol-2-yl]carbonyl $\} a m i n o)-1 H$-pyrrol- 
2-yl]carbonyl \}amino)ethylcarbamate $(\mathbf{8 c})(0.100 \mathrm{~g}, 0.15 \mathrm{mmol})$ was dissolved in DCM (3 mL) and trifluoroacetic acid $(3 \mathrm{~mL})$ and the solution refluxed for $30 \mathrm{~min}$. The solvents where then removed under reduced pressure to yield the amine salt. This was then dissolved in $80 \%$ aqueous ethanol $(3 \mathrm{~mL})$, potassium carbonate $(0.080 \mathrm{~g}$, $0.30 \mathrm{mmol}$ ) is then added followed by ( $E$ )-phenyl $N^{\prime}$-cyano- $N$-methylcarbamimidate $(0.052 \mathrm{~g}, 0.30 \mathrm{mmol})$ the solution was then refluxed over night. The solution was then allowed to cool to room temperature before removing the solvent under reduced pressure; the residue was then dissolved in DMF and purified by HPLC to yield the desired product as a yellow solid ( $27 \mathrm{mg}, 27 \%$ ), Mp. $>230{ }^{\circ} \mathrm{C}$, purity by HPLC $=97 \%$ IR $\nu_{\max }: 3438,3137,2908,1628,1530$ and $1353 \mathrm{~cm}^{-1} .{ }^{1} \mathrm{H}$ NMR [DMSO- $\left.d_{6}, 500 \mathrm{~Hz}\right]: \delta_{\mathrm{H}} 2.68(3 \mathrm{H}, \mathrm{d}, J=4.65 \mathrm{~Hz}), 3.24(2 \mathrm{H}, \mathrm{m})$, 3.27(2H, m), $3.80(3 \mathrm{H}, \mathrm{s}), 3.87(3 \mathrm{H}, \mathrm{s}), 6.89(1 \mathrm{H}, \mathrm{d}, J=1.7 \mathrm{~Hz}), 7.00(1 \mathrm{H}$, $\mathrm{m}), 7.09(1 \mathrm{H}, \mathrm{d}, J=1.7 \mathrm{~Hz}), 7.21(1 \mathrm{H}, \mathrm{d}, J=1.7 \mathrm{~Hz}), 7.35(1 \mathrm{H}, \mathrm{d}, J=1.7 \mathrm{~Hz})$, $7.66(3 \mathrm{H}, \mathrm{m}), 7.80(3 \mathrm{H}, \mathrm{m}), 8.01(5 \mathrm{H}, \mathrm{m}), 8.11(1 \mathrm{H}, \mathrm{m}), 8.61(1 \mathrm{H}, \mathrm{s}), 9.28$ $(1 \mathrm{H}, \mathrm{s}), 9.95(1 \mathrm{H}, \mathrm{s}), 10.36(1 \mathrm{H}, \mathrm{s})$. HRFABMS: Found: 643.2887; calculated for $\mathrm{C}_{35} \mathrm{H}_{35} \mathrm{~N}_{10} \mathrm{O}_{3}{ }^{+}, 643.2888$.

\subsubsection{7. $N-(5-\{[(2-\{[(E)-($ Cyanoimino $)($ methylamino $)$ methyl $] a m i n o\}$} ethyl)amino]carbonyl\}-1-methyl-1H-pyrrol-3-yl)-4-(\{4-[(E)-2-(3methoxyphenyl)ethenyl]benzoyl\}amino)-1-methyl-1H-pyrrole-2carboxamide (12b)

$\mathrm{N}$-(5-\{[(2-Aminoethyl)amino]carbonyl $\}$-1-methyl-1H-pyrrol-3yl)-4-(\{4-[(E)-2-(3-methoxyphenyl)ethenyl]benzoyl $\} a m i n o)-1-m e$ thyl-1H-pyrrole-2-carboxamide (10b) $(20 \mathrm{mg}, 0.03 \mathrm{mmol})$ in ethanol $(4 \mathrm{~mL})$ to which phenyl $N^{\prime}$-cyano- $N$-methylimidocarbamate (30 $\mathrm{mg}, 0.17 \mathrm{mmol}$ ) and potassium carbonate (17 $\mathrm{mg}, 0.13 \mathrm{mmol}$ ) were added. The reaction mixture was heated under reflux for 4 days in a sealed tube. Solvent was removed under reduced pressure and the crude product was purified by HPLC; fractions containing the required product were collected and freeze-dried to give the desired product as a pale yellow solid $(0.008 \mathrm{~g}, 43 \%)$ with no distinct melting point. IR $\nu_{\max }: 2170,1639,1464,1436,1405,1268,1206$, 1050, 964 and $777 \mathrm{~cm}^{-1}$. ${ }^{1} \mathrm{H}$ NMR [DMSO- $d_{6}, 500 \mathrm{~Hz}$ ]: $\delta_{\mathrm{H}} 10.32(1 \mathrm{H}$, s), $9.95(1 \mathrm{H}, \mathrm{s}), 8.12(1 \mathrm{H}, \mathrm{t}, J=5.5 \mathrm{~Hz}), 7.97(2 \mathrm{H}, \mathrm{d}, J=8.5 \mathrm{~Hz}), 7.74$ $(2 \mathrm{H}, \mathrm{d}, J=8.5 \mathrm{~Hz}), 7.36-7.29(4 \mathrm{H}, \mathrm{m}), 7.22-7.20(3 \mathrm{H}, \mathrm{m}), 7.09(1 \mathrm{H}, \mathrm{d}$, $J=1.8 \mathrm{~Hz}), 7.00-6.99(2 \mathrm{H}, \mathrm{m}), 6.89(1 \mathrm{H}, \mathrm{d}, J=1.8 \mathrm{~Hz}), 6.87-6.86(1 \mathrm{H}$, $\mathrm{m}), 3.87(3 \mathrm{H}, \mathrm{s}), 3.81(3 \mathrm{H}, \mathrm{s}), 3.80(3 \mathrm{H}, \mathrm{s}), 3.31(2 \mathrm{H}, \mathrm{q}, J=7.0 \mathrm{~Hz}), 3.25$ $(2 \mathrm{H}, \mathrm{q}, J=7.0 \mathrm{~Hz}), 2.69(3 \mathrm{H}, \mathrm{d}, J=4.6 \mathrm{~Hz})$. HRESIMS: Found: 622.2885; calculated for $\mathrm{C}_{33} \mathrm{H}_{36} \mathrm{O}_{4} \mathrm{~N}_{9} 622.2885$.

4.3.18. Amino( $\{2-[(\{4-[(\{4-[(\{6-[(E)-2-(4-m e t h o x y p h e n y l) e t h e n y l]-$ 3-pyridinyl\}carbonyl)amino]-1-methyl-1H-pyrrol-2-yl\}carbonyl) amino]-1-methyl-1H-pyrrol-2-yl\}carbonyl)amino]ethyl\}amino) methaniminium trifluoroacetate (13a)

tert-Butyl-2-[(\{4-[(\{4-[(\{6-[(E)-2-(4-methoxyphenyl)ethenyl]3-pyridinyl\}carbonyl) amino]-1-methyl-1H-pyrrol-2-yl\}carbonyl) amino]-1-methyl-1H-pyrrol-2-yl \}carbonyl) amino]ethylcarbamate (8a) (20 mg, $0.03 \mathrm{mmol}$ ) was dissolved in DCM (3 mL) and trifluoroacetic acid ( $3 \mathrm{~mL}$ ) and the solution refluxed for $30 \mathrm{~min}$. The solvents were then removed under reduced pressure to yield the amine salt. This was then dissolved in $80 \%$ aqueous ethanol ( $3 \mathrm{~mL}$ ), potassium bicarbonate $(0.015 \mathrm{~g}, 0.06 \mathrm{mmol})$ was then added followed by amino(methylsulfanyl) methaniminium sulphate $(0.010 \mathrm{~g}, 0.06 \mathrm{mmol})$. The solution was then heated under reflux over night. The solution was then allowed to cool to room temperature before removing the solvent under reduced pressure, the residue was then dissolved in DMF and purified by HPLC to yield the desired product as a yellow/orange solid (2 $\mathrm{mg}, 11 \%$ ), Mp. $>230{ }^{\circ} \mathrm{C}$, purity by HPLC $=96 \%$. IR $\nu_{\max }: 3452,3124,2941,1630$, 1521 and $1240 \mathrm{~cm}^{-1} .{ }^{1} \mathrm{H}$ NMR [DMSO- $d_{6}, 500 \mathrm{~Hz}$ ]: $\delta_{\mathrm{H}} 3.10(2 \mathrm{H}, \mathrm{m}$, $\left.\mathrm{CH}_{2}\right), 3.20\left(2 \mathrm{H}, \mathrm{m}, \mathrm{CH}_{2}\right), 3.81\left(6 \mathrm{H}, \mathrm{m}, \mathrm{NCH}_{3}\right.$ and $\left.\mathrm{OCH}_{3}\right), 3.89(3 \mathrm{H}, \mathrm{s}$, $\left.\mathrm{NCH}_{3}\right), 6.86(3 \mathrm{H}, \mathrm{m}, \mathrm{Ar}-\mathrm{H}, \mathrm{NH}), 7.00(2 \mathrm{H}, \mathrm{d}, \mathrm{Ar}-\mathrm{H}, J=8.8 \mathrm{~Hz}), 7.10$ $(1 \mathrm{H}, \mathrm{d}, \mathrm{Ar}-\mathrm{H}, J=1.8 \mathrm{~Hz}), 7.21(1 \mathrm{H}, \mathrm{d}, \mathrm{Ar}-\mathrm{H}, J=1.8 \mathrm{~Hz}), 7.27(1 \mathrm{H}, \mathrm{d}$,
$(\mathrm{C}=\mathrm{C}-\mathrm{H}), J=16.1 \mathrm{~Hz}), 7.35(1 \mathrm{H}, \mathrm{d}, \mathrm{Ar}-\mathrm{H}, J=1.8 \mathrm{~Hz}), 7.67(3 \mathrm{H}, \mathrm{m}$, $\mathrm{Ar}-\mathrm{H}), 7.76(1 \mathrm{H}, \mathrm{d},(\mathrm{C}=\mathrm{C}-\mathrm{H}), J=16.1 \mathrm{~Hz}), 8.02(1 \mathrm{H}, \mathrm{t}, \mathrm{NH}$, $J=5.6 \mathrm{~Hz}), 8.27(1 \mathrm{H}, \mathrm{d}$ of d, $\mathrm{Ar}-\mathrm{H}, J=2.30$ and $8.2 \mathrm{~Hz}), 9.05(1 \mathrm{H}, \mathrm{d}$, $\mathrm{Ar}-\mathrm{H}, J=2.2 \mathrm{~Hz}), 9.96(1 \mathrm{H}, \mathrm{s}, \mathrm{NH}), 10.48(1 \mathrm{H}, \mathrm{s}, \mathrm{NH})$. HRFABMS: Found: 585.2769; calculated for $\mathrm{C}_{30} \mathrm{H}_{35} \mathrm{~N}_{9} \mathrm{O}_{4}{ }^{+}, 585.2769$.

\subsubsection{9. $N-(5-\{[(2-\{[$ Amino(imino $) m e t h y l] a m i n o\} e t h y l) a m i n o]$} carbonyl $\}$-1-methyl-1H-pyrrol-3-yl)-4- $(\{4-[(E)-2-(3-$ methoxyphenyl)ethenyl]benzoyl\}amino)-1-methyl-1H-pyrrole-2carboxamide (13b)

$N$-(5-\{[(2-Aminoethyl)amino]carbonyl $\}-1-m e t h y l-1 H$-pyrrol-3yl)-4-(\{4-[(E)-2-(3-methoxyphenyl)ethenyl]benzoyl \}amino)-1-me thyl-1H-pyrrole-2-carboxamide (10b) $(16 \mathrm{mg}, 0.03 \mathrm{mmol}$ ) was dissolved in ethanol $(4 \mathrm{~mL})$. Potassium carbonate $(17 \mathrm{mg}$, $0.13 \mathrm{mmol}$ ) and methyl imidothiocarbamate hydroiodide (33 $\mathrm{mg}$, $0.12 \mathrm{mmol}$ ) were added and the solution was heated under reflux for $48 \mathrm{~h}$. Solvent was removed under reduced pressure and the crude product was purified by HPLC; fractions containing the right material were collected and freeze-dried to give the required product as a pale yellow solid (4 mg, 23\%) with no distinct melting point. IR $\nu_{\max }: 1691,1583,1536,1510,1436,1362,1270,1201,1146$, 1069 and $778 \mathrm{~cm}^{-1} .{ }^{1} \mathrm{H}$ NMR [DMSO- $d_{6}, 500 \mathrm{~Hz}$ ]: $\delta_{\mathrm{H}} 10.35(1 \mathrm{H}, \mathrm{s})$, $9.98(1 \mathrm{H}, \mathrm{s}), 8.13(1 \mathrm{H}, \mathrm{t}, J=5.5 \mathrm{~Hz}), 7.99(2 \mathrm{H}, \mathrm{d}, J=8.5 \mathrm{~Hz}), 7.76(2 \mathrm{H}$, $\mathrm{d}, J=8.5 \mathrm{~Hz}), 7.46(1 \mathrm{H}, \mathrm{t}, J=5.5 \mathrm{~Hz}), 7.39-7.31(4 \mathrm{H}, \mathrm{m}), 7.23-7.22$ ( $2 \mathrm{H}, \mathrm{m}), 7.20(1 \mathrm{H}, \mathrm{d}, J=1.8 \mathrm{~Hz}), 7.12(1 \mathrm{H}, \mathrm{d}, J=1.8 \mathrm{~Hz}), 6.98(1 \mathrm{H}, \mathrm{d}$, $J=1.8 \mathrm{~Hz}), 6.91-6.88(1 \mathrm{H}, \mathrm{m}), 3.88(3 \mathrm{H}, \mathrm{s}), 3.83(3 \mathrm{H}, \mathrm{s}), 3.82(3 \mathrm{H}, \mathrm{s})$, 3.33-3.27 $(4 \mathrm{H}, \mathrm{m})$. HRESIMS: Found, 583.2770; calculated for $\mathrm{C}_{31} \mathrm{H}_{35} \mathrm{O}_{4} \mathrm{~N}_{8}, 583.2776$.

4.3.20. $\mathrm{N}-(5-\{[(2-\{[$ Amino(imino)methyl $] a m i n o\} e t h y l) a m i n o]$ carbonyl\}-1-methyl-1H-pyrrol-3-yl)-1-methyl-4-(\{4-[(E)-2-(3quinolinyl)ethenyl]benzoyl\}amino)-1H-pyrrole-2-carboxamide trifluoroacetate $(\mathbf{1 3 c})$

This material was prepared using an analogous procedure to that for (13a) from (8c) as an orange solid in (11 $\mathrm{mg}, 16 \%$ yield), m.p. $>230^{\circ} \mathrm{C}$, purity by HPLC $=97 \%$. IR $\nu_{\max }: 3371,2938,1650,1580$ and $1353 \mathrm{~cm}^{-1}$. ${ }^{1} \mathrm{H}$ NMR [DMSO- $d_{6}, 500 \mathrm{~Hz}$ ]: $\delta_{\mathrm{H}} 3.26\left(2 \mathrm{H}, \mathrm{m}, \mathrm{CH}_{2}\right), 3.35$ $\left(2 \mathrm{H}, \mathrm{m}, \mathrm{CH}_{2}\right), 3.82$ (3H, s, N-Me), 3.88 (3H, s, N-Me), 6.98 (1H, d, $\mathrm{Ar}-\mathrm{H}, J=1.7 \mathrm{~Hz}), 7.16(1 \mathrm{H}, \mathrm{d}, \mathrm{Ar}-\mathrm{H}, J=1.7 \mathrm{~Hz}), 7.19(1 \mathrm{H}, \mathrm{d}, \mathrm{Ar}-\mathrm{H}$, $J=1.7 \mathrm{~Hz}), 7.36(1 \mathrm{H}, \mathrm{d}, \mathrm{Ar}-\mathrm{H}, J=1.7 \mathrm{~Hz}), 7.63(3 \mathrm{H}, \mathrm{m}, \mathrm{Ar}-\mathrm{H}), 7.75$ $(1 \mathrm{H}, \mathrm{m}, \mathrm{Ar}-\mathrm{H}), 7.81(2 \mathrm{H}, \mathrm{m}, \mathrm{Ar}-\mathrm{H}), 8.03(4 \mathrm{H}, \mathrm{m}, \mathrm{Ar}-\mathrm{H}), 8.55(1 \mathrm{H}, \mathrm{d}$, $\mathrm{Ar}-\mathrm{H}, J=2.1 \mathrm{~Hz}), 8.93(1 \mathrm{H}, \mathrm{m}, \mathrm{N}-\mathrm{H}), 9.25(1 \mathrm{H}, \mathrm{d}, \mathrm{Ar}-\mathrm{H}, J=2.1 \mathrm{~Hz})$, $9.96(1 \mathrm{H}, \mathrm{s}, \mathrm{N}-\mathrm{H}), 10.36(1 \mathrm{H}, \mathrm{d}, \mathrm{N}-\mathrm{H})$. LRMS: Found: 604.27 calculated for $\mathrm{C}_{33} \mathrm{H}_{34} \mathrm{~N}_{9} \mathrm{O}_{3}{ }^{+}, 604.27$.

\subsubsection{3- $((E)-2-\{4-[(\{1-M e t h y l-5-[(\{1-m e t h y l-5-[(\{2-$}

[(trifluoroacetyl)amino]ethyl\}amino)carbonyl]-1H-pyrrol-3-yl\} amino)carbonyl]-1H-pyrrol-3-yl\}amino)carbonyl]phenyl\}ethenyl) quinolinium trifluoroacetate $(\mathbf{1 4 c})$

$3-[(E)-2-(4-\{[(5-\{[(5-\{[(2-$ Ammonioethyl $)$ amino $]$ carbonyl $\}-1-$ methyl-1H-pyrrol-3-yl)amino]carbonyl $\}-1-m e t h y l-1 H$-pyrrol-3-yl) amino]carbonyl phenyl)ethenyl] quinolinium bis(trifluoroacetate) (8c) $(20 \mathrm{mg}, 0.025 \mathrm{mmol}$ ) was dissolved in DMF (1 mL, dry) and to this was added triethylamine ( $5 \mathrm{mg}, 0.05 \mathrm{mmol}$ ). After $30 \mathrm{~min}$ of stirring, trifluoroacetic acid anhydride ( $5 \mathrm{mg}, 0.025 \mathrm{mmol}$ ) was added dropwise and left to stir for $16 \mathrm{~h}$. The reaction mixture was subjected to HPLC purification to obtain the desired product (10 mg, 50\% yield), with no distinct melting point. IR $\nu_{\max }: 3421$, 2961, 2928, 2851, 1706, 1682, 1650, 1440, 1204 and $723 \mathrm{~cm}^{-1} .{ }^{1} \mathrm{H}$ NMR [DMSO- $d_{6}, 500 \mathrm{~Hz}$ : $\delta_{\mathrm{H}} 10.15(1 \mathrm{H}, \mathrm{s}), 9.75(1 \mathrm{H}, \mathrm{s}), 9.25(1 \mathrm{H}, \mathrm{bs})$, $9.23(1 \mathrm{H}, \mathrm{d}, J=2.0), 8.51(1 \mathrm{H}, \mathrm{d}, J=2.0), 7.97-8.03(5 \mathrm{H}, \mathrm{m}), 7.92(1 \mathrm{H}$, $\mathrm{m}), 7.55-7.81(5 \mathrm{H}, \mathrm{m}), 7.30(1 \mathrm{H}, \mathrm{d}, J=2.0), 7.17(1 \mathrm{H}, \mathrm{d}, J=2.0), 7.09$ $(1 \mathrm{H}, \mathrm{d}, J=2.0), 6.97(1 \mathrm{H}, \mathrm{d}, J=2.0), 3.88(3 \mathrm{H}, \mathrm{s}), 3.820(3 \mathrm{H}, \mathrm{s}), 3.359$ $(4 \mathrm{H}, \mathrm{m})$. HRESIMS: Found: 658.2390 calculated for $\mathrm{C}_{34} \mathrm{H}_{31} \mathrm{O}_{4} \mathrm{~N}_{7} \mathrm{~F}_{3}$, 658.2384 . 
4.3.22. $N-(5-\{[(5-\{[(2-H y d r o x y e t h y l) a m i n o]$ carbonyl $\}-1-m e t h y l-$ 1H-pyrrol-3-yl)amino]carbonyl\}-1-methyl-1H-pyrrol-3-yl)-6-[(E)2-(4-methoxyphenyl)ethenyl]nicotinamide (16a)

2-[(\{4-[(\{4-[(\{6-[(E)-2-(4-Methoxyphenyl)ethenyl]-3-pyridinyl $\}$ carbonyl)amino]-1-methyl-1H-pyrrol-2-yl\}carbonyl)amino]-1-me thyl-1H-pyrrol-2-yl\}carbonyl)amino]ethyl acetate (9a) (0.100 g, $0.17 \mathrm{mmol}$ ) was dissolved in ethanol ( $1 \mathrm{~mL})$, a solution of sodium hydroxide $(0.020 \mathrm{~g}, 0.5 \mathrm{mmol})$ in water $(5 \mathrm{~mL})$ was then added and the solution allowed to reflux for $2 \mathrm{~h}$. The whole solution was then freeze dried and the residue purified by HPLC to give the title compound as an orange solid $(0.020 \mathrm{~g}, 23 \%), \mathrm{Mp} .>230{ }^{\circ} \mathrm{C}$, purity by $\mathrm{HPLC}=98 \%$. IR $\nu_{\text {max }}: 1342,2926,1632,1593,1261 \mathrm{~cm}^{-1} \cdot{ }^{1} \mathrm{H}$ NMR [DMSO- $\left.d_{6}, 500 \mathrm{~Hz}\right]: \delta_{\mathrm{H}} 3.24\left(2 \mathrm{H}, \mathrm{q}, \mathrm{CH}_{2}, J=5.5 \mathrm{~Hz}\right), 3.81(6 \mathrm{H}$, $\mathrm{m}, \mathrm{NCH}_{3}$ and $\left.\mathrm{OCH}_{3}\right), 3.87\left(3 \mathrm{H}, \mathrm{s}, \mathrm{NCH}_{3}\right), 3.46\left(2 \mathrm{H}, \mathrm{t}, \mathrm{CH}_{2}\right.$, $J=5.5 \mathrm{~Hz}), 6.86(1 \mathrm{H}, \mathrm{d}, \mathrm{Ar}-\mathrm{H}, J=1.9 \mathrm{~Hz}), 7.00(2 \mathrm{H}, \mathrm{d}, \mathrm{Ar}-\mathrm{H}$, $J=8.8 \mathrm{~Hz}), 7.07(1 \mathrm{H}, \mathrm{d}, \mathrm{Ar}-\mathrm{H}, J=1.9 \mathrm{~Hz}), 7.18(1 \mathrm{H}, \mathrm{d}, \mathrm{Ar}-\mathrm{H}$, $J=1.8 \mathrm{~Hz}), 7.24(1 \mathrm{H}, \mathrm{d},(\mathrm{C}=\mathrm{C}-\mathrm{H}), J=16.1 \mathrm{~Hz}), 7.35(1 \mathrm{H}, \mathrm{d}, \mathrm{Ar}-$ $\mathrm{H}, J=1.8 \mathrm{~Hz}), 7.66(3 \mathrm{H}, \mathrm{m}, \mathrm{Ar}-\mathrm{H}), 7.77(1 \mathrm{H}, \mathrm{d},(\mathrm{C}=\mathrm{C}-\mathrm{H})$, $J=16.0 \mathrm{~Hz}), 7.91(1 \mathrm{H}, \mathrm{t}, \mathrm{NH}, J=5.6 \mathrm{~Hz}), 8.25(1 \mathrm{H}, \mathrm{d}$ of $\mathrm{d}, \mathrm{Ar}-\mathrm{H}$, $J=2.3$ and $8.2 \mathrm{~Hz}), 9.06(1 \mathrm{H}, \mathrm{d}, \mathrm{Ar}-\mathrm{H}, J=2.2 \mathrm{~Hz}), 9.93(1 \mathrm{H}, \mathrm{s}$, $\mathrm{NH}), 10.46(1 \mathrm{H}, \mathrm{s}, \mathrm{NH})$. HRFABMS: Found: 543.2314 calculated for $\mathrm{C}_{31} \mathrm{H}_{33} \mathrm{~N}_{6} \mathrm{O}_{6}{ }^{+}, 543.2311$.

4.3.23. $\mathrm{N}-(5-\{[(2-H y d r o x y e t h y l) a m i n o] c a r b o n y l\}-1-m e t h y l-1 H-$ pyrrol-3-yl)-4-(\{4-[(E)-2-(3-methoxyphenyl)ethenyl]benzoyl $\}$ amino)-1-methyl-1H-pyrrole-2-carboxamide (16b)

2-(\{[4-(\{[4-(\{4-[(E)-2-(3-Methoxyphenyl)ethenyl]benzoyl $\} a m i$ no)-1-methyl-1H-pyrrol-2-yl]carbonyl \}amino)-1-methyl-1H-pyrrol-2-yl]carbonyl\}amino)ethyl acetate (9b) $(20 \mathrm{mg}, 0.03 \mathrm{mmol})$ was dissolved in ethanol $(1 \mathrm{~mL})$ to which was added sodium hydroxide solution $(2.4 \mathrm{mg}, 0.06 \mathrm{mmol}, 2$ molar equivalent in water $1 \mathrm{~mL}$ ) The reaction mixture was heated under reflux for $2 \mathrm{~h}$ then the solvents were removed under reduced pressure. The crude product was purified by HPLC. Fractions containing the required material were collected and freeze-dried to give the required compound as a white solid $(0.010 \mathrm{~g}, 62 \%)$ with no distinct melting point. IR $\nu_{\max }: 3432,1639,1585,1520,1437,1403,1346$, 1274, 1206, 1046 and $777 \mathrm{~cm}^{-1} .{ }^{1} \mathrm{H}$ NMR [DMSO- $d_{6}, 500 \mathrm{~Hz}$ ]: $\delta_{\mathrm{H}}$ $10.31(1 \mathrm{H}, \mathrm{s}), 9.94(1 \mathrm{H}, \mathrm{s}), 7.97(2 \mathrm{H}, \mathrm{d}, J=8.5 \mathrm{~Hz}), 7.92(1 \mathrm{H}, \mathrm{t}$, $J=5.5 \mathrm{~Hz}), 7.74(2 \mathrm{H}, \mathrm{d}, J=8.5 \mathrm{~Hz}), 7.36-7.30(4 \mathrm{H}, \mathrm{m}), 7.22-7.20$ $(3 \mathrm{H}, \mathrm{m}), 7.08(1 \mathrm{H}, \mathrm{d}, J=1.8 \mathrm{~Hz}), 6.89-6.87(2 \mathrm{H}, \mathrm{m}), 4.66(1 \mathrm{H}, \mathrm{br}$, $\mathrm{OH}), 3.87(3 \mathrm{H}, \mathrm{s}), 3.81(3 \mathrm{H}, \mathrm{s}), 3.80(3 \mathrm{H}, \mathrm{s}), 3.48(2 \mathrm{H}, \mathrm{t}, J=5.8 \mathrm{~Hz})$, $3.26(2 \mathrm{H}, \mathrm{q}, J=5.8 \mathrm{~Hz})$. HRESIMS: Found: 542.2402 calculated for $\mathrm{C}_{30} \mathrm{H}_{32} \mathrm{O}_{5} \mathrm{~N}_{5}, 542.2398$.

\subsubsection{Phenyl $N^{\prime}$-cyano- $N$-methylimidocarbamate}

Phenyl $N^{\prime}$-cyano- $N$-methylimidocarbamate was prepared according to the published procedure [14]

\subsubsection{Methyl imidothiocarbamate hydroiodide}

Methyl imidothiocarbamate hydroiodide was prepared according to the published procedure [15]

\subsection{Thermal denaturation experiments}

DNA oligomers and their complements were melted at a rate of $0.5^{\circ} \mathrm{C} / \mathrm{min}$ in $10 \mathrm{mM}$ PBS buffer solution (pH 7.4) with $50 \mathrm{mM} \mathrm{NaCl}$ on a Cary 300 BIO UV-visible spectrophotometer fitted with a peltier temperature controller. Programs were set and data was processed using Cary WinUV software.

Each oligomer made to a concentration of $6 \times 10^{-6} \mathrm{M}$ was mixed with sufficient MGB to give the appropriate ratio. Samples were heated from $10^{\circ} \mathrm{C}$ to $80^{\circ} \mathrm{C}$ and cooled from $80^{\circ} \mathrm{C}$ to $10^{\circ} \mathrm{C}$ with the spectra being recorded at $260 \mathrm{~nm}$ during both of these cycles. The melting temperatures $\left(T_{\mathrm{m}}\right)$ of the hybrids were determined from the derivative maxima [16]. This process was repeated a total of 4 times to ensure repeatability of the experiment which showed an average error of $\pm 0.5^{\circ} \mathrm{C}$.

\section{Acknowledgements}

The authors would like to thank Dr J. Parkinson, Craig Irving, Patricia Keating, Denise Gilmour and Gavin Bain for all the help and support which they have provided during the course of this research work.

\section{Appendix A. Supplementary material}

Supplementary data related to this article can be found online at http://dx.doi.org/10.1016/j.ejmech.2012.08.013.

\section{References}

[1] A.I. Khalaf, A.J. Drummond, B. Pringle, I. McGroarty, G.G. Skellern, R.D. Waigh, C.J. Suckling, J. Med. Chem. 47 (2004) 2133-2156.

[2] N. Anthony, D. Breen, J. Clarke, G. Donoghue, A. Drummond, E. Ellis, C. Gemmell, J.-J. Helesbeux, I. Hunter, A.I. Khalaf, S. Mackay, J. Parkinson, C.J. Suckling, R.D. Waigh, J. Med. Chem. 50 (2007) 6116-6125.

[3] C.J. Suckling, J. Phys. Org. Chem. 21 (2008) 575-583.

[4] A.M. Aronov, Drug Discov. Today 10 (2) (2005) 149-155.

[5] W. Treesuwan, K. Wittayanarakul, N.G. Anthony, G. Huchet, H. Alniss, S. Hannongbua, A.I. Khalaf, C.J. Suckling, J.A. Parkinson, R.D. Waigh, S.P. Mackay, Phys. Chem. Chem. Phys. 11 (2009) 10682-10693.

[6] N.G. Antony, A.I. Khalaf, S.P. Mackay, J.A. Parkinson, C.J. Suckling, R.D. Waigh, J. Am. Chem. Soc. 126 (2004) 11338-11349.

[7] D. Breen, A.R. Kennedy, C.J. Suckling, Org. Biomol. Chem. 7 (2009) 179-186.

[8] J. Klose, M. Bienert, C. Mollenkopf, D. Wehle, C. Zhang, L.A. Carpino, P. Henklein, Chem. Commun. (1999) 1847-1848.

[9] A.J. Hampshire, H. Khairallah, A.I. Khalaf, A.H. Ebrahimabadi, R.D. Waigh, C.J. Suckling, T. Brown, K.R. Fox, Bioorg. Med. Chem. Lett. 16 (13) (2006)3469-3474.

[10] (a) C. Jamieson, E.M. Moir, Z. Rankovic, G. Wishart, J. Med. Chem. 49 (17) (2006) 5029-5046;

(b) M.C. Sanguinetti, M. Tristani-Firouzi, Nature 440 (23) (2006) 463-469.

[11] A.J. Hampshire, D.A. Rusling, V.J. Broughton-Head, K.R. Fox, Methods 42 (2007) $128-140$.

[12] A.J. Hampshire, K.R. Fox, Anal. Biochem. 374 (2008) 298-303.

[13] A.J. Hampshire, K.R. Fox, Biochimie 90 (2008) 988-998.

[14] P. Igel, R. Geyer, A. Strasser, S. Dove, R. Seifert, A. Buschauer, J. Med. Chem. 52 (20) (2009) 6297-6313.

[15] X. Chen, J. Wang, S. Sun, J. Fan, S. Wu, J. Liu, S. Ma, L. Zhang, X. Peng, Bioorg. Med. Chem. Lett. 18 (1) (2008) 109-113.

[16] I. Afonina, M. Zivarts, I. Kutyavin, E. Lukhtanov, H. Gamper, R.B. Meyer, Nucleic Acids Res. 25 (13) (1997) 2657-2660. 